\title{
Absence of subcerebral projection neurons delays disease onset and extends survival in a mouse model of ALS
}

Thibaut Burg $^{1}$, Charlotte Bichara ${ }^{2}$, Jelena Scekic-Zahirovic ${ }^{1}$, Mathieu Fischer ${ }^{1,3}$, Geoffrey Stuart-Lopez ${ }^{1}$, François Lefebvre ${ }^{4}$, Matilde Cordero-Erausquin ${ }^{2} \&$ Caroline Rouaux $^{1^{*}}$

${ }^{1}$ Inserm UMR_S 1118, Mécanismes centraux et périphériques de la neurodégénérescence, Faculté de Médecine, Université de Strasbourg, Strasbourg, France.

${ }^{2}$ UPR 3212, Institut des neurosciences cellulaires et intégratives, UPR 3212 CNRS, Université de Strasbourg, Strasbourg, France.

${ }^{3}$ Current address: Department of Paediatrics, John Radcliffe Hospital, University of Oxford, Oxford, UK.

${ }^{4}$ GMRC, service de santé publique, Hôpitaux Universitaires de Strasbourg, Strasbourg, France.

*Correspondence should be addressed to C.R. (caroline.rouaux@inserm.fr)

\section{Acknowledgments}

The work has been supported by a European Research Council (ERC) starting grant \#639737, a Marie Curie career integration grant \#618764, an "Association Française contre les Myopathies" (AFM)-Telethon trampoline grant \#16923 and a Neurex grant to CR, PhD fellowships from the French Ministry of Research to TB and CB, followed by the "Fondation pour la Recherche sur le Cerveau" (FRC) to TB and the "Association de Recherche sur la Sclérose Latérale Amyotrophique" (ARSLA) to CB. JCZ was supported by a post-doctoral fellowship from the AFM-Telethon. The authors are extremely thankful to Véronique Marchand-Pauvert, Pascal Branchereau, Pierre Veinante and Luc Dupuis for critical reading of the manuscript, and insightful comments. 


\begin{abstract}
Amyotrophic Lateral Sclerosis (ALS) is a fatal neurodegenerative disease of adulthood that affects voluntary motricity and rapidly leads to full paralysis and death. ALS arises from the combined degeneration of motoneurons in the spinal cord and brain stem, responsible for muscle denervation, and corticospinal projection neurons (CSN), responsible for emergence of the upper motor neuron syndrome. Recent studies carried on ALS patients suggest that the disease may initiate in the motor cortex and spread to its projection targets. However, this “corticofugal hypothesis" of ALS has not yet been specifically challenged. Here, we provide a direct test of this hypothesis by genetically removing subcerebral projection neurons (SubCerPN), including CSN, in $S o d 1^{G 86 R}$ mice, a mouse model of ALS. Ablation of the transcription factor Fezf2, leading to the complete absence of all SubCerPN, delays disease onset, reduces weight loss and motor impairment, and increases survival without modifying disease duration. Importantly absence of SubCerPN and CSN also limits pre-symptomatic hyperreflexia. Together, our results demonstrate that major corticofugal tracts are critical to ALS onset, and that SubCerPN and CSN in particular may carry detrimental signals to their downstream targets. In its whole, this study provides first experimental arguments in favour of the corticofugal hypothesis of ALS.
\end{abstract}

\title{
Key words
}

Amyotrophic lateral sclerosis; corticospinal neurons; cerebral cortex; Sod1 ${ }^{G 86 R}$; corticofugal hypothesis 


\section{Introduction}

Amyotrophic lateral sclerosis (ALS) is a devastating neurodegenerative disease characterized by rapidly progressing muscle atrophy and paralysis, leading to death within only two to five years of diagnosis. Clinically and histologically, ALS is defined as the combined and progressive loss of two broad neuronal populations involved in motor control: the corticospinal and corticobulbar neurons (CSN, or upper motor neurons) in the motor cortex, and the spinal and bulbar motoneurons (MN, or lower motor neurons) in the brain stem and spinal cord $[8,63]$. This duality of targeted neuronal populations and affected regions of the central nervous system has fostered a long-time debate regarding the origin of the disease along the cortico-spino-muscular axis (reviewed in [54]).

The French Neurologist Jean-Martin Charcot who provided the first description of ALS suggested a cortical origin of the disease and a descending propagation from the motor cortex to the spinal cord [11]. Following Charcot's histological description of the disease, comprehensive clinical examination of ALS patients unravelled series of signs highly suggestive of a cortical origin of the disease, such as the split hand syndrome and typical gait abnormalities for instance [19]. Meanwhile, trans-cranial magnetic stimulation studies unravelled early hyperexcitability of the motor cortex that characterizes both sporadic and familial ALS patients, negatively correlates with survival, and manifests prior to disease onset, pointing to a potential role of the motor cortex in disease initiation [67]. Cortical hyperexcitability has been proposed to translate into glutamatergic excitotoxicity to the downstream targets of the corticospinal neurons, the alpha motoneurons of the brain stem and spinal cord, providing a first possible mechanism for corticospinal propagation [18]. More recently, the proposed staging of TDP-43 pathology [6], a histopathological burden that characterizes the vast majority of ALS patients, led to the emergence of the so-called 
corticofugal hypothesis. According to it, the disease may originate in the motor cortex and misfolded TDP-43 proteins may disseminate to the direct, mono-synaptic targets of cortical projection neurons along the main corticofugal routes with a prion-like mechanism [5]. If corticofugal propagation is supported by longitudinal diffusion tensor imaging studies with tractography or connectome analysis of ALS patients $[32,66]$, it cannot be directly tested in patients. In spite of the heavy differences that exist between species, and in particular the uniqueness of the Human and primate corticomotoneuronal system [18], we reasoned that mouse genetics could prove useful to directly address a potential cortical origin and corticofugal propagation of ALS.

In rodents, like in Humans, corticofugal projections arise from two broad populations of excitatory projection neurons, i.e., the subcerebral projection neurons (SubCerPN) and the corticothalamic projection neurons $(\mathrm{CThN})$ [41]. CThN are located in the cortical layer VI and connect the cerebral cortex to numerous thalamic nuclei, that connect back to the cerebral cortex, creating a loop of reciprocal sensory processing [7]. SubCerPN are located in the cortical layer $\mathrm{V}$ and connect the various areas of the cerebral cortex to their most distant targets. While the thalamus is affected by the TDP-43 pathology as early as stage 2 [6], and shows impairment in imaging studies [14], no major contribution of CThN to ALS has been suspected. SubCerPN instead include, amongst other subpopulations, the disease-relevant corticospinal neurons (CSN) that connect the cerebral cortex to the spinal cord. While major differences exist between primates and rodents regarding the route of the corticospinal tract within the spinal cord, and the connectivity mode of the CSN onto the alpha motoneurons, i.e. both mono- and pluri-synaptic in primates, and essentially pluri-synaptic in adult mice [36], it is worth highlighting that many mouse models of the disease recapitulate CSN or SubCerPN degeneration $[22,28,38,42,50,70,71]$. In this regard, we recently showed that $\operatorname{Sod} 1^{G 86 R}$ mice 
not only display pre-symptomatic CSN degeneration, but also that CSN and spinal motoneuron degeneration are somatotopically related [42], similarly to what had been described in ALS patients $[46,53,72]$.

Here, we sought to test the contribution of CSN and other SubCerPN to disease onset and progression by taking advantage of the Fezf2 knock-out mice [29] that develop in absence of SubCerPN. These animals lack the gene encoding a master transcription factor that is both necessary $[12,13,39,40,48]$ and sufficient to instruct the birth and specification of CSN and other SubCerPN from embryonic cortical progenitors $[12,39,48]$ but also from non-cortical neural progenitors and even post-mitotic neurons of another lineage [57,58]. We thus crossbred the SodI $1^{G 86 R}$ and the $F e z f 2^{-/}$mouse lines to generate a model that ubiquitously expresses a mutant of the murine Sodl gene, a condition sufficient to develop ALS-like symptoms and premature death $[16,42,56,59]$, but entirely lacks CSN and other SubCerPN, hence challenging ALS definition. 


\section{Materials and Methods}

\section{Animals}

All animal experiments were performed under the supervision of authorized investigators and approved by the local ethical committee of Strasbourg University (CREMEAS, agreements \# 00738.01). Animals were housed in the animal facility of the Faculty of Medicine of Strasbourg, with a regular 12 hours light/dark cycle, under constant conditions $\left(21 \pm 1^{\circ} \mathrm{C} ; 60 \%\right.$ humidity). Standard soft laboratory food and water were accessible ad libitum throughout all experiments. BAC transgenic $\operatorname{Sod} 1^{G 86 R}$ mice [56] were obtain from the animal facility of the Faculty of Medicine of Strasbourg, and knockout $F e z f 2^{-/}$mice were generated by Hirata and colleagues [29] and kindly provided by the Arlotta Lab. Mice were genotyped by PCR of genomic DNA from tail biopsies as previously described $[29,56]$. Sod1 ${ }^{G 86 R}$ males were

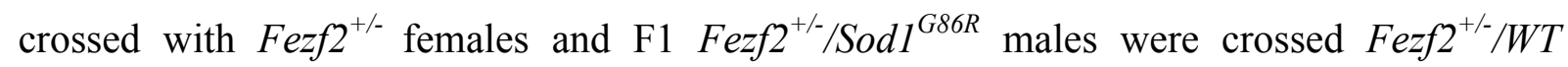
females. The F2 generation provided four genotypes of interest: $F e z f 2^{+/+} / W T$; $F e z 2^{+/+} / \operatorname{Sod1}{ }^{G 86 R} ; \quad F e z f 2^{-/} / W T ; \quad F e z f 2^{-/} / S o d 1^{G 86 R}$. Males were used for survival and behavioural studies and end-stage histology. Males and females, in equal proportions, were used for H-reflex and histology at pre-symptomatic ages. Mice were followed daily, and disease progression was rated according to a clinical scale going from score 4 to 0 , as previously described [42]. End-stage animals were euthanized upon reaching score 0, i.e. when they were no longer unable to roll over within $10 \mathrm{~s}$ after being gently placed on their back [42]. Disease onset was calculated as the time of peak of body weight.

\section{qPCR analyses}

Cortex and spinal cord were harvested and rapidly frozen in liquid nitrogen and stored at $80^{\circ} \mathrm{C}$ until analysis. Total RNA was extracted using TRIzol reagent (Invitrogen) and stainlesssteel bead in a Tissue Lyser (Qiagen). $1 \mu \mathrm{g}$ of RNA was reverse transcribed using the iScript 
cDNA synthesis kit (Bio-Rad). Quantitative PCR (qPCR) was performed with the IQ SYBR Green Supermix (Bio-Rad). Gene expression was normalized by calculating a normalization factor using Gusb, Actb and Hsp90ab1 as reference genes. The following primer sequences were used for qPCR:

Gusb: $\quad$ F-CGAGTATGGaGCAGACGCAA; R-AGCCTTCTGGTACTCCTCACT

Actb: $\quad$ F-ATGTGGATCAGCAAGCAGGA; R-AGCTCAGTAACAGTCCGCCT

Hsp90abl: F-TACTACTCGGCTTTCCCGTCA; R-CCTGAAAGGCAAAGGTCTCCA

Fezf2: F-GTGCGGCAAGGTGTTCAATG; R-CAGACTTTGCACACAAACGGT

Sod1: F-GAGACCTGGGCAATGTGACT; R-GTTTACTGCGCAATCCCAAT

ChAT: F-CTGGCCACCTACCTTCAG-TG; R-CCCCAAACCGCTTCACAATG

\section{Motor tests and regression analyses}

For all motor tests, mice were trained from 5 to 8 weeks of age, and then followed from 9 weeks of age until death, on a daily basis for general health and neurological symptoms, twice a week for body weight and muscle grip strength, and once a week for inverted grid test, accelerating rotarod and CatWalk. Each motor session consisted of three trials and the results represent the mean of these three trials. Motor coordination and endurance were assessed using rotarod (Ugobasile model 7650), with trials of 300 seconds composed of an acceleration period of 150 seconds (4-20 rpm) followed by constant speed period of 150 seconds. Muscle strength was measured using a strength grip meter (Bioseb, BIO-GS3). Four limbs hang test that allows measuring the ability of mice to use sustained limb tension to oppose gravitational force was used as previously described $[10,60]$. Briefly, mice were placed on a cage grid, allowed to accommodate to their environment for 3-5 seconds before the grid was slowly inverted and positioned $35 \mathrm{~cm}$ above a receiving cage filled with $5-6 \mathrm{~cm}$ of bedding. The hanging time corresponds to the time the mice spent hung to the grid before dropping it. Mouse gait was analysed with the CatWalk XT (Noldus Information Technology). This 
automated gait analysis system allows digitalizing each individual footprint during the mouse locomotion and generates numerous parameters for quantitative and qualitative analysis of individual footprint and gait [65] (Supplementary Table 1). Recordings were performed under the conditions previously described [60]. Each mouse was allowed to cross freely the recording field of the runway with three independent attempts. Criteria for data collection were $i$ ) crossing the field in less than 10 seconds and ii) a walking speed variation of less than $60 \%$. Multiple linear regression analyses were run on R 3.4 .3 with all the relevant packages. They allowed including weight only (Grip Test, Rotarod, Inverted Grid) or weight and speed (all Catwalk parameters except for the speed itself) as confounding variables. Normality of the distributions was tested using the Shapiro-Wilk test or the Kolmogorov-Smirnov test, and was assessed graphically using a normal quantile plot.

\section{Electromyography}

All recordings were performed with a standard EMG apparatus (Dantec) on mice anesthetized with a solution of Ketamine (Imalgène $1000 ®$, Merial; $90 \mathrm{mg} / \mathrm{kg}$ body weight) and Xylazine (Rompun $2 \% \AA$, Bayer; $16 \mathrm{mg} / \mathrm{kg}$ body weight) and kept under a heating mat to maintain physiological muscle temperature $\left(\approx 31^{\circ} \mathrm{C}\right)$. Electrical activity was monitored on muscles of both limbs for at least 2 minutes, as previously described [59].

\section{Tail spasticity}

Tail spasticity of end stage mice was determined and quantified as previously described [20]. Briefly, a monopolar needle electrode (Medtronic, 9013R0312, diameter $0.3 \mathrm{~mm}$ ) was inserted in segmental tail muscles of paralyzed mice to record reflex activity. Muscles spasms were evoked with mechanical stimulation of the tail. For quantification, signal intensities 
were measured before and after stimulation, using ImageJ $(\mathrm{NIH})$, and the signal-to-noise ratio was calculated.

\section{H-reflex recording}

H-reflex was assessed on both hindlimbs (with a three weeks interval) of pre-symptomatic mice aged of 80 and 105 days, by modifying a previously described method [35]. Mice were anesthetized with a solution of Ketamine (Imalgène $1000 \AA$, Merial; 90mg/kg body weight) and Xylazine (Rompun $2 \%{ }^{\circledR}$, Bayer; $16 \mathrm{mg} / \mathrm{kg}$ body weight) and placed on a heating pad. After unilateral exposure of the sciatic nerve, a spherical homemade stimulation electrode was placed around the nerve. A recording monopolar needle electrode (Medtronic, 9013R0312, diameter $0.3 \mathrm{~mm}$ ) was transcutaneously placed in the abductor digiti minimi muscles and recordings were obtained with an amplifier (Digitimer Ldt, DS3). A first stimulation of $0.2 \mathrm{~ms}$ at $0.1 \mathrm{~Hz}$ was initially applied, followed by gradually increasing current intensity. This protocol allowed us to find the minimal intensity to elicit a M-response and the intensity to obtain a maximal M-response, in order to fix the stimulation intensity at approximately $50 \%$ of the M-response. For each animal, we tested the presence or absence of the H-reflex by performing 10 sciatic nerve stimulations at $0.1 \mathrm{~Hz}, 0.2 \mathrm{~Hz}, 0.5 \mathrm{~Hz}$ and $1 \mathrm{~Hz}$. For each of the 10 traces, we measured the maximal amplitude (peak value - through value) of the noise, on a $1 \mathrm{~ms}$ window between stimulation and M-Wave ( $\Delta$ Noise). We measured similarly the amplitude of the H-Reflex as the peak-through value of the recording on a $1 \mathrm{~ms}$ window situated at the expected latency for the H-reflex, between 5 and $8 \mathrm{~ms}$ following stimulation ( $\Delta$ Response). The mean and standard deviation of the $\Delta$ Noise were measured from the $10 \Delta$ Noise values obtained from the 10 successive traces for each animal, and used to calculate the Z-scores. The Z-score of each response to the stimulation site was calculated using the following equation: 


$$
\mathrm{Z}-\text { score }=\frac{\Delta \text { Response }- \text { mean } \Delta \text { Noise }}{\text { standard deviation of } \Delta \text { Noise }}
$$

A Z-score of 3, corresponding to a significance level of 0.001 , was chosen to discriminate significant responses from non-significant ones. This conservative threshold was chosen in agreement with visual inspection of the traces, to ensure that any H-reflex response was not simply due to noise. H-reflex and F-waves share some electrophysiological properties, but Fwave's persistence, defined as the number of significant responses divided by the number of stimuli, is mainly independent of stimulation frequency, or only tends to increase above 1$2 \mathrm{~Hz}$ stimulations rates $[21,43]$. To ensure that the considered signal was an H-reflex, we thus measured the persistence of the response across increasing stimulations rates, and only considered signals not demonstrating persistence (Supplementary Fig.2). After recording, mice were stitched and kept under a heating lamp until recovery. Mice were then monitored for recovery and subjected to daily checks. Mice were considered to display H-reflex when at least one of the two legs was positive.

\section{Retrograde labelling of the CSN}

CSN were labelled as previously described [42]. Briefly, animals were deeply anesthetized with an intraperitoneal injection of Ketamine (Imalgène $1000 \AA$, Merial; $120 \mathrm{mg} / \mathrm{kg}$ body weight) and Xylazine (Rompun $2 \%{ }^{\circledR}$, Bayer; $16 \mathrm{mg} / \mathrm{kg}$ body weight) solution and placed on a heating pad. Laminectomy was performed in the $\mathrm{C} 3-\mathrm{C} 4$ cervical region of the spinal cord, and the dura was punctured using a pulled glass capillary lowered to the dorsal funiculus. Five pressure microinjections of $23 \mathrm{nl}$ of Fluorogold (Fluorchrome) were performed on each side of the dorsal funiculus (Drummond Scientific, Nanoject II). Five days after injection, mice followed the histological procedure (see below).

\section{Histological procedures}


Animals were deeply anesthetized with an intraperitoneal injection of Ketamine (Imalgène $1000 \AA$, Merial; $120 \mathrm{mg} / \mathrm{kg}$ body weight) and Xylazine (Rompun 2\% ${ }^{\circledR}$, Bayer; $16 \mathrm{mg} / \mathrm{kg}$ body weight), and transcardially perfused with cold $0.01 \mathrm{M}$ PBS, followed by cold $4 \%$ PFA in 0.01 M PBS. Brains, spinal cords, gastrocnemius and tibialis were post-fixed in the same fixative solution overnight (nervous tissues) or for 1 hour (muscles) and stored in PBS $0.1 \mathrm{M}$ at $4{ }^{\circ} \mathrm{C}$ until use. Fixed brains and spinal cords were cut in $40 \mu \mathrm{m}$ thick sections on a vibratome (Leica Biosystems, S2000). Fluorogold-labelled brains were mounted on slides with DPX mounting solution (Sigma-Aldrich). Immunostainings on brains and spinal cords were performed on slides at room temperature. First, sections were immersed in $3 \%$ hydrogen peroxide $\left(\mathrm{H}_{2} \mathrm{O}_{2}\right)$ to remove the endogenous peroxidase activity and washed with phosphate buffered saline (PBS). Unspecific binding sites were blocked with 5\% horse serum and $0.5 \%$ triton X-100 in PBS for 30 min and incubated with primary antibody overnight. After rinsing in PBS, sections were incubated biotinylated secondary antibody for 2 hours, rinsed in PBS and incubated 1 hour with the Vectasatin ABC Kit (Vector Laboratories, PK7200). Revelation was performed by incubating the sections in $0.075 \%$ 3, 3'-diaminobenzidine tetrahydrochloride (Sigma-Aldrich, D5905) and $0.002 \% \mathrm{H}_{2} \mathrm{O}_{2}$ in 50mM Tris $\mathrm{HCl}$. Lumbar (L2-L3) spinal motor neurons from six sections covering a distance of $640 \mu \mathrm{m}$ were immunolabelled using a goat anti-choline acetyltransferase (ChAT) antibody (Merk Millipore, AB144P, 1/50) and a biotinylated donkey anti-goat IgG (Jackson, 1/500). Antibody for other spinal cord immunostainings were: rat anti CTIP2 (Abcam, 18465, 1/100), mouse anti P62 (Abcam, 56416, 1/100), rabbit anti GFAP (Dako, Z0334, 1/200), goat anti Ibal (Abcam AB5076, 1/100) and corresponding biotinylated secondary antibody (Jackson, 1/500). Serotonergic neurons of the median and dorsal raphe nuclei from individual coronal sections located at Bregma $-4.72 \mathrm{~mm}$ were immunolabelled with a goat anti-TPH2 antibody (Abcam, AB121013, 1/500), followed by a donkey anti-goat biotinylated secondary antibody (Jackson, 1/500). Tibialis anterior muscles 
were dissected into bundles and processed for immunofluorescence using a combination of rabbit anti-synaptophysin and rabbit anti-neurofilament antibodies (Eurogentec) followed by an Alexa-conjugated donkey anti-rabbit 488 (Jackson, 1/1 000), and rhodamine conjugated $\alpha$ bungarotoxin (Sigma-Aldrich, T0195), as previously described [42]. On average 100 NMJ per animals were examined. Images were captured using an AxioImager.M2 microscope (Zeiss) equipped with a structured illumination system (Apotome, Zeiss) and a high-resolution B/W camera (Hamamatsu), and run by the ZEN 2 software (Zeiss). Experimenters blinded to the genotypes performed the neuronal counts and NMJ assessments.

\section{Statistical Analysis}

Data are presented as mean \pm standard error of the mean (SEM). Statistical analysis was performed using GraphPad Prism 6 (GraphPad, CA). For comparison between two groups, Student's t-test was used and for three or more groups, 1-way analysis of the variance followed by Tukey's multiple comparison post hoc test was applied. If there were 2 variables, 2-way analysis of the variance followed by Tukey's multiple comparison post hoc test was applied. For survival and disease onset analysis, animals were evaluated using log-rank test (Mantel-Cox). Grubbs'test or ESD method (extreme studentized deviate) has excluded one mouse of our survival experiment. Fischer exact test was used to determine significant different proportion. Results were considered significant when $\mathrm{p}<0.05$. 


\section{Results}

\section{Generation of the $\mathrm{Fezf} 2^{-/-}$; Sod1 ${ }^{G 86 R}$ mice}

To test the contribution of the motor cortex and more broadly the cerebral cortex to ALS onset and progression, we generated a mouse line that overexpresses the mutant murine Sod1 ${ }^{G 86 R}$ transgene but lacks one of the most important cortical output, the SubCerPN. We crossbred Sod1 ${ }^{G 86 R}$ mice, a well-established model of ALS [16,56,59], to mice knocked out for the gene encoding the transcription factor Fezf2 and that develop in absence of cortical layer V SubCerPN [29,48] (Fig. 1a). As previously reported, retrograde labelling of CSN, a subpopulation of SubCerPN, by injection of Fluorogold in the cervical portion of the dorsal funiculus, in the spinal cord of 75 day-old animals, revealed labelled pyramidal cells in the layer $\mathrm{V}$ of the motor area of $\mathrm{Fezf}^{+/+}(W T)$ mice but not in that of $\mathrm{Fezf}^{-/-}(\mathrm{KO})$ mice (Fig. 1b). We ran two steps of crossbreeding to obtain four genotypes of interest: Fezf2 $2^{+/+}$and nontransgenic (WT), Fezf2 $2^{-/}$and non-transgenic $(K O), F e z f 2^{+/+}$and $S o d 1^{G 86 R}(\operatorname{Sod} 1)$, and Fezf2 ${ }^{-/-}$ and $\operatorname{Sod} 1^{G 86 R}(K O / S o d 1)$ (Fig. 1a). To further verify the absence of SubCerPN in $K O$ and KO/Sod1 animals, we performed a fluorescent immunostaining to reveal CTIP2, a transcription factor expressed in the large nuclei of layer V SubCerPN, and in the smaller nuclei of layer VI CThN [1]. Microscopic analysis of coronal sections revealed the absence of CTIP2-positive layer V SubCerPN in $K O$ and $K O / S o d l$ animals compared to their $W T$ and Sod1 littermates (Fig. 1c). To check that absence of Fezf2 expression and of SubCerPN had no effect on Sod1 expression or on spinal motoneurons (MN) generation and specification, we ran qPCR analysis in the cerebral cortex and lumbar spinal cord of 75 day-old animals (Fig. 1d). Up-regulation of $\operatorname{Sod} 1$ expression was verified in $\operatorname{Sod} 1$ and $\mathrm{KO} / \mathrm{Sod} 1$ animals and did not differ between the two genotypes, neither in the cerebral cortex nor in the spinal cord (Fig. 1d). Finally, expression of the motoneuronal marker Chat was not significantly different between any of the four genotypes, ruling out the possibility that absence of SubCerPN, and 
more particularly of CSN may have a detrimental effect on spinal MN birth and specification (Fig. 1d), in accordance with the fact that Fezf2 is not expressed in the spinal cord $[29,48]$. Together, the data suggest that KO/Sodl mice may represent a good model to study the impact of SubCerPN on ALS-like onset and progression, and to test the corticofugal hypothesis.

\section{Absence of SubCerPN delays disease onset and death}

To examine the consequences of the absence of projections from the cerebral cortex to its main subcerebral targets, we assessed and compared general clinical parameters of Sodl and $\mathrm{KO} / \mathrm{Sod} 1$ mice and their controls. Weight loss is a hallmark of ALS and negatively correlates with survival in ALS patients [17]. Similarly, Sod1 ${ }^{G 86 R}$ mice start losing weight before onset of motor deterioration, and weight maintenance is positively correlated with their survival [16]. Fezf2 deficient mice present a smaller weight gain compared to wild type mice [29], a condition that could per se be detrimental in a context of ALS [17]. Weight analysis of 75 day-old animals confirmed that $K O$ mice were indeed lighter than $W T$ mice, and revealed, as expected, that $\mathrm{KO} / \mathrm{Sod} 1$ were also lighter than Sodl animals. Body mass index analysis on another cohort of animals revealed that reduced weight was associated with reduced size and that $K O$ and $K O / S o d l$ mice were smaller but not thinner than their $W T$ and $W T / S o d l$ littermates (data not shown). At this age, we observed no difference either between Sodl and $W T$ or between $\mathrm{KO} / \mathrm{Sodl}$ and $\mathrm{KO}$ mice (Fig. 2a). Long-term weight follow-up showed that both $W T$ and $K O$ mice regularly gained weight, but that Sodl and KO/Sodl mice instead stopped gaining weight prematurely (Fig. 2b). This arrest of weight gain, or peak of weight, is often used a measure of disease onset in ALS mouse models [4,16]. KO/Sod1 mice presented a significant delay of disease onset compared to their Sod1 littermates (Median: 107.5 days vs 159 days; $\mathrm{p}=0.0070$ ) (Fig. $2 \mathrm{c}$ ). Similarly, the survival of the KO/Sodl mice was increased 
compared to that of Sod1 mice (Median: 130 days vs 183 days; $\mathrm{p}=0.0083$ ) (Fig. 2d), but the overall disease duration was not significantly different between the two genotypes (Fig.2e). Finally, the weight loss during the course of the disease was significantly smaller for the KO/Sodl mice than it was for the Sod1 mice $(36.45 \pm 1.82 \%$ vs $25.07 \pm 1.68 \% ; \mathrm{p}<0.0001)$ (Fig.2f), in accordance with an arrest of weight gain rather that a clear weight loss, as seen also on the longitudinal weight follow-up (Fig. 2b), and an increased survival. Together, the data indicate that, in the $\operatorname{Sod} 1^{G 86 R}$ mouse model of ALS, absence of SubCerPN is beneficial as it delays disease onset and death, and limits weight loss during the course of the disease.

\section{Absence of SubCerPN attenuates motor impairment}

We next tested whether absence of SubCerPN could also ameliorate motor performances, and more particularly muscle strength, assessed by grip and inverted grid tests, motor coordination, assessed on accelerating Rotarod, and gait, assessed by CatWalk (Fig. 3 and 4). Because $K O$ and $K O / S o d l$ mice displayed initially a smaller weight, and because Sodl and $\mathrm{KO} / \mathrm{Sod} 1$ lost weight during the course of the disease, we ran linear regression analysis using the weight as a co-variable in order to better compare the performances of the different groups of animals (Fig. 3g-i and Supplementary Table 1). We ran two series of three comparisons: $W T$ vs $S o d 1, W T$ vs $K O$, and $K O$ vs $K O / S o d 1$, both at the time when the experiment was initiated (Origin, Supplementary Table 1) and over the course of the experiment (Fig. 3g-i, and Slope, Supplementary Table 1). On the grip test and Rotarod, $W T$ and $K O$ mice displayed similar performances and maintained them over time (Fig. 3a,b). Sodl and KO/Sodl mice instead rapidly showed decreased performances (Fig. 3a,b and g,h), but KO/Sodl mice were affected later than their Sod1 littermates (Fig. 3d,e) and maintained higher performances over time than their Sodl littermates (Fig. 3a,b and 3g,h). On inverted grid, $K O$ and KO/Sodl mice initially displayed more difficulty in opposing their gravitational force compared to $W T$ and 
Sodl mice, and this in spite of their smaller weight (Fig. 3c and i). Yet, while $W T$ and $K O$ animals maintained their hanging time throughout all the repetitive assessments, Sodl and KO/Sod1 saw their performances gradually decreasing (Fig. 3c,i). This decrease occurred later in KO/Sodl animals than in Sodl animals (Fig. 3f). In addition, the impairment rate of KO/Sodl was milder than that of Sod1 (Fig. 3c,i), and, by disease end stage, the KO/Sodl performed better than the Sod1 (Fig. 3c,i). Linear regression analyses of the grip strength, and inverted grid test, indicated that significant differences existed between the $W T$ and $K O$ animals initially (Origin, Supplementary Table $1, \mathrm{p}<0.001$ ), but that over time they evolved in a similar manner (Fig. 3g,i and Slope, Supplementary Table 1, NS). Such differences were expected given that absence of SubCerPN implies absence of corticospinal neurons and discrete modifications of the motor behaviour in mice, without evolution over time. Importantly, linear regression analyses of the grip strength, the Rotarod and the inverted grid data, over time, indicated significant differences between $K O$ and $K O / S o d l$ animals further confirming that absence of SubCerPN moderated motor deterioration in mice (Fig. 3g-i).

CatWalk gait analysis device allows testing more than 200 parameters that can be classified into five broad categories: run characterization, temporal, spatial, kinetic and inter-limb coordination parameters [9]. We ran linear regression analyses on the CatWalk data, using not only the weight as a covariate, but also the speed, already shown to greatly influence numerous gait parameters [2] (Fig. 4 and Supplementary Table 1). We identified 3 spatial parameters that were significantly different between $W T$ and $K O$ animals over time, and not between $W T$ and Sodl animals and that likely reflect the consequences of the absence of CSN on the gait: the Max Contact Area, the Print Width Mean, and the Print Area Mean ( $W T$ vs $K O$, Supplementary Table 1, Slope). We also identified 15 parameters that were significantly altered in Sod1 mice compared to WT mice during disease progression (Supplementary Table 1, Slope). Amongst them, 10 were also significantly different in Sod1 vs KO/Sodl animals 
(Supplementary Table 1, Slope and Fig. 4). Of those, two parameters showed opposite effects between absence of Fezf2 and overexpression of Sod1 ${ }^{G 86 R}$, such as the Print Position of the Right and Left Paws (Fig. 4k,1; Inter-limb coordination parameter), and eight parameters showed instead a genuine amelioration of the Sod1 phenotype (WT vs Sod1) by the absence CNS: the Stand Index (Fig. 4c; temporal parameter), the Max Contact Max Intensity Mean (Fig.4d; spatial parameter) and the Mean Intensity Mean (Fig. 4e; spatial parameter) the Print Length Mean (Fig. 4f; spatial parameter), the Max Intensity Mean (Fig. 4g; spatial parameter) and the Mean Intensity Mean (Fig. 4h; spatial parameter), the Max Intensity of the 15 Most Intense Pixels Mean (Fig. 4i; spatial parameter) and the Number of Steps (Fig. 4j; run characterization parameter). Taken in its whole, this analysis indicates that absence of CSN, per se, modifies a small set of spatial gait parameters, but ameliorates a larger set of spatial, temporal, inter-limb coordination and run characterization parameters that are affected in Sod1 $1^{G 86 R}$ animals as disease progresses. Together, the data confirm the beneficial effects of absence of CSN and other SubCerPN on motor impairment.

\section{Absence of CSN minimizes spinal MN loss and neuromuscular junction denervation without modifying other pathological hallmarks of ALS}

To better understand how absence of SubCerPN could be beneficial in the neurodegenerative context of ALS, we further investigated the spinal cord of end-stage animals, for its relevance to ALS but also as the target of CSN, a subpopulation of SubCerPN. To this aim, we ran series of immunolabellings on coronal sections of lumbar spinal cords harvested from endstage animals and their age-matched control littermates (Fig. 5 and Supplementary Fig. 1). Staining for the astrogliosis and microgliosis markers GFAP and IBA1 revealed reactive gliosis in the lumbar spinal cord of end-stage Sodl and KO/Sodl animals (Supplementary Fig. 1), but no difference could be observed between these two genotypes. Labelling of the 
autophagy marker P62/SQTM1 revealed a healthy, homogeneous cytoplasmic labelling in both $W T$ and $K O$ mice, and large, stellate-like inclusions in the spinal cords of Sodl and KO/Sod1 mice (Supplementary Fig. 1), with similar occurrence and intensity between the two genotypes. Immunolabelling and counting of the ChAT-positive motor neurons (MN) present in the ventral horn of the lumbar spinal cord revealed a mild decrease of the number of MN somas by disease end-stage in Sodl mice (Fig. 5a,b), as we previously reported [42,59]. Interestingly, KO/Sodl animals maintained a significantly bigger pool of ChAT-positive MN compare to Sodl animals $(8.456 \pm 0.49$ vs $6.152 \pm 0.57$; $=0.0306$; Fig. 5a,b). Spinal MN loss in ALS follows a Wallerian degeneration with an initial denervation of the neuromuscular junctions (NMJ), a consecutive retrograde deterioration of the axons and a final shrinkage and loss of the somas [23]. Thus, to further test whether the mitigation of the motor impairments displayed by $\mathrm{KO} / \mathrm{Sod} 1$ mice in comparison with the Sodl mice reflected the state of the NMJ, we labelled the NMJ of the tibialis anterior muscle of end-stage Sod 1 and $\mathrm{KO} / \operatorname{Sod} 1$ mice and their aged-matched $W T$ and $K O$ littermates (Fig. 5c). Rating of the NMJ integrity into three categories, innervated, partly denervated and fully denervated, followed by statistical analyses indicated that $\mathrm{KO} / \mathrm{Sod} 1$ animals had twice more innervated NMJ than Sod1 animals by disease end-stage $(23.8 \pm 4.87 \%$ vs $11.34 \pm 3.12 \%$; p = 0.0239; Fig. $5 d)$. As a whole, the data show that absence of cortical afferences partly protects NMJ denervation and Wallerian degeneration of the $\mathrm{MN}$, and suggest that this partial protection may be independent from local gliosis and altered autophagy.

\section{Absence of CSN positively impacts hyperreflexia but not spasticity}

In Humans, degeneration or lesion of the corticospinal tract results in appearance of the upper motor neuron syndrome [52], a series of symptoms that include muscular weakness, decreased motor control, altered muscle tone, hyperreflexia, including spasticity, and clonus 
[31]. Most ALS patients suffer from spasticity with different degrees of severity [63]. Spasticity is a painful manifestation, defined by J.W. Lance as "a motor disorder characterised by a velocity-dependent increase in tonic stretch reflexes (muscle tone) with exaggerated tendon jerks, resulting from hyperexcitability of the stretch reflex, as one component of the upper motoneuron syndrome" [34]. In ALS patients, hyperreflexia can be measured as the increase of the short latency Hoffman's reflex, or H-reflex [61]. In rodents, H-reflex per se, or the ratio of amplitudes of $\mathrm{H}-$ reflex to compound muscle action potentials ( $\mathrm{H} / \mathrm{M}$ ratio) were shown to increase with spasticity [3,47], and long lasting tail muscle activity following cutaneous stimulation was proposed as a simple method to assess spasticity in awake animals [3]. We reasoned that the mouse line that we generated could contribute to assess the role of CSN in the modulation of spinal network excitability involved in hyperreflexia and spasticity, in an ALS-related context.

First, we ran electromyographic analyses on pre-symptomatic mice aged of 80 days (left leg) and 105 days (right leg) in order to detect H-reflex in anaesthetized mice by stimulation of the sciatic nerve and recording in the abductor digiti minimi muscle (Fig. 6a). To verify that the recorded wave that followed the $\mathrm{M}$ wave was an $\mathrm{H}$-reflex and not a confounding $\mathrm{F}$ wave, known to exhibit similar latencies, we verified that it disappeared with increased stimulus intensity frequency [26] (Supp. Fig. 2). We could detect an H-reflex in fractions of Sod1 and $K O / S o d 1$ groups of animals, but never in the $W T$ or $K O$ animals (Fig. 6a,b). This indicates that, under our experimental conditions, H-reflex could develop only in Sod1 ${ }^{G 86 R}$ animals, independently of the presence of CSN, and that, counter-intuitively, absence of CSN, per se, was not sufficient to trigger an H-reflex (Fig. 6a). Next, we evaluated the proportions of presymptomatic animals presenting an H-reflex in either one of the two legs tested (Fig. 6b). No significant difference between Sodl and KO/Sodl could be seen at this age. However, measurement of the $\mathrm{H} / \mathrm{M}$ ratio amongst the animals displaying an $\mathrm{H}$ reflex showed a 
significant reduction in $\mathrm{KO} / \mathrm{Sod} 1$ animals compared to their Sodl littermates (Fig. 6c). This suggests that at pre-symptomatic ages, absence of CSN limits hyperreflexia.

A more integrated assessment of spasticity is the electromyographic evaluation of the tail long lasting reflex (LLR) in awake and fully paralyzed animals prior to harvesting (Fig. 6d-f) $[3,15,20]$. At disease end stage, the $\operatorname{Sod} 1$ and $\mathrm{KO} / \operatorname{Sod} 1$ groups of animals could be subdivided into spastic and non-spastic, but the relative proportions of each was not significantly different between the two genotypes (Fig. 6e). Among spastic animals, intensity of the response to the stimulation was not significantly different between the Sodl and $\mathrm{KO} / \mathrm{Sod} 1$ groups (Fig. 6f). The data suggest that absence of CSN is not sufficient to prevent the manifestation of spasticity in end-stage animals.

Spasticity of end-stage $S o d 1^{G 86 R}$ and $S O D 1^{G 37 R}$ mouse models of ALS has previously been linked to serotonergic neuron degeneration in the raphe nuclei $[15,20]$. We thus tested whether absence of CSN and other SubCerPN could affect the population of TPH2-positive neurons present in the raphe nuclei over the course of the disease in Sodl and KO/Sodl, compared to their $W T$ and $K O$ littermates (Fig. 7). As previously reported [15], end-stage Sod1 mice displayed a significant loss of TPH2-positive neurons compared to $W T$ (Fig. 7b,c). Similarly, we observed a significant loss of TPH2-positive neurons in end-stage $\mathrm{KO} / \mathrm{Sod} 1$ mice compared to $W T$, but no significant difference between Sodl and KO/Sodl animals (Fig. $7 b, c)$. At younger ages, no significant difference could be detected across the different groups of mice. Thus, the data suggest that the parallel loss of serotonergic neurons in end-stage Sod1 and $\mathrm{KO} / \mathrm{Sod} 1 \mathrm{mice}$ could, at least in part, contribute to the emergence of LLR in end-stage animals, and that absence of CSN and other SubCerPN does not affect serotonergic neurons survival.

Altogether, the data indicate that hyperreflexia evidenced by an increase of the $\mathrm{H} / \mathrm{M}$ ratio arises pre-symptomatically in $\operatorname{Sod} 1^{G 86 R}$ mice, and that absence of CSN decreases this 
particular feature of the upper motor neuron syndrome. Contrastingly, spasticity, evidenced by emergence of the LLR in end-stage $\operatorname{Sod} 1^{G 86 R}$ animals, does not appear to be modulated by the presence or absence of CSN and other SubCerPN, but could, as already demonstrated $[15,20]$, rather arise from the loss of another descending control onto spinal networks, the serotonergic neurons of the raphe nuclei. In mouse models of ALS, H/M ratio may thus represent a better readout of the upper motor neuron syndrome than tail LLR. 


\section{Discussion}

In the current study, we sought to test the corticofugal hypothesis of ALS in a welldefined mouse model of the disease. We generated a mouse line overexpressing the $\operatorname{Sod} 1^{G 86 R}$ transgene, a condition sufficient to induce rapidly progressing motor deterioration, premature death and histopathological hallmarks of ALS, but also deficient for the gene Fezf2 and thus lacking all SubCerPN, the major contributor to the corticofugal projections. Importantly, absence of SubCerPN also implied absence of CSN, a situation that challenged the clinical and histopathological definitions of ALS as the combined degeneration of both MN and CSN. In comparison with single transgenic Sodl animals, the resulting double mutant $\mathrm{KO} /$ Sod 1 mice presented a delayed disease onset, extended survival, along with improved clinical conditions during disease duration as assessed by decreased weight loss and improved motor performances. In addition, Sodl animals presented pre-symptomatic hyperreflexia, a classical feature of the upper motor neuron syndrome, that was also found limited by the absence of SubCerPN and CSN. Together these findings support the corticofugal hypothesis of ALS and may help refocusing pre-clinical research to the cerebral cortex and its neuronal populations.

\section{Contribution of the cerebral cortex and its outputs to ALS}

While the origin of ALS remains a debated question [54], recent evidences from neurophysiological and pathological studies conducted on patients $[6,67]$ are nourishing a revival of interest for Charcot's initial view of the disease as a primarily cortical impairment [11]. Indeed, whether disease propagation relies on altered neuronal excitability and subsequent excitotoxicity [67], or on prion-like propagation of misfolded proteins [5], both schools of thought converge to a common cortical origin of ALS and propagation along the corticofugal tracts $[18,24]$. While several clinical features support a cortical origin of the disease [19], and recent longitudinal imaging analyses suggest a propagation of impairments 
along the corticofugal tracts, $[32,66]$, the hypothesis cannot be tested in patients. If the corticomotoneuronal system has undergone major modifications with evolution [18], it is important to highlight as well the similarities of excitatory cortical neuron subtypes between Human and mouse [30], and to acknowledge that the highest differences arise from the important evolution of the cortico-cortical projection neurons (commissural and associative/intrahemispheric), as opposed to the corticofugal neurons [30,44]. Indeed, corticothalamic sub-populations and subclasses of SubCerPN, i.e. cortico-striatal, corticotectal, cortico-pontine and cortico-spinal, are well conserved between mouse and Human (reviewed in [44]), suggesting that, while not perfect, rodents may rather be good models to study the contribution of SubCerPN to ALS, and to directly test the corticofugal hypothesis.

Further supporting the appropriateness of rodents in general and mice in particular to cortical impairment in ALS, is their ability to recapitulate CSN $[28,42,50,70,71]$ or SubCerPN degeneration $[22,38]$. In that respect, we recently completed a comprehensive spatiotemporal analysis of CSN degeneration in the $\operatorname{Sod} 1^{G 86 R}$ mouse model of ALS, and described a loss of CSN that precedes that of MN and even NMJ denervation. In this model, CSN and MN degenerations are also somatotopically related, suggesting that cortical impairment precedes MN impairment [42]. Of further relevance to Human disease, it is noteworthy that CSN loss also starts before weight loss, pointing to the earliness of cortical impairment in these animals $[16,42]$. This is further revealed in the present study by the pre-symptomatic occurrence of hyperreflexia in sub-groups of $\operatorname{Sod} 1$ and $\mathrm{KO} / \mathrm{Sod} 1$ animals, which brings here a functional evidence of early impairment of the CSN. Thus, the rodent models in general and Sod1 $1^{G 86 R}$ mice in particular seem appropriate to assess the contribution of CSN and other SubCerPN to ALS, and to test whether CSN degeneration may be detrimental to downstream MN by lack of protective input, or instead be beneficial by limiting the propagation of a toxic input from the motor cortex. 


\section{Absence of SubCerPN delays onset and extends survival without increasing disease duration}

In this study, we sought to assess specifically the contribution of CSN and other SubCerPN to disease onset and progression in mice. To this aim, we crossbred the Sod1 $1^{\text {G86R }}$ and the $\mathrm{Fezf}^{-/-}$mouse lines to generate a model that ubiquitously expresses a mutant of the murine Sodl gene [56] but lacks CSN and other SubCerPN [29,48], hence challenging ALS pathological and clinical definitions. Our data indicate that absence of SubCerPN delays disease onset and increases survival without modifying disease duration. The results are highly reminiscent of an elegant study by Thomsen and colleagues who knocked-down mutant SOD1 transgene in the posterior motor cortex of the SOD1 $1^{G 93 A}$ rat model of ALS [62]. The authors chose an AAV9 virus to selectively transduce neurons. AAV9-SOD1-shRNA injections delayed disease onset and extended survival without affecting disease duration [62]. The similarity of the results between this study and ours is remarkable given the broad differences of the two approaches. First, while in $\operatorname{Sod} 1^{G 86 R}$ mice, CSN degenerate long before $\mathrm{MN}$ [42], CSN degeneration is secondary to MN loss in the $S O D 1^{G 93 A}$ rats [62]. Second, while $\operatorname{Sod} 1^{G 86 R}$ mice were crossed to the Fezf2 KO mice to prevent any direct connection between the motor cortex and its targets, the knocked-down of the SOD1 $1^{G 93 A}$ transgene in rats was undertaken to favour the maintenance of a functional pool of CSN. Together, the two sets of data suggest that absence of diseased CSN or instead maintenance of genetically corrected CSN may be equally beneficial, and that Sod1/SOD1 mutant transgene-expressing CSN may be detrimental to their downstream targets. Yet, it is worth mentioning that AAV9 likely targeted all types cortical excitatory projection neurons and inhibitory interneurons, and could have contributed to correct more broadly the cortical circuit dysfunctions which have been reported in the $S o d 1^{G 93 A}$ and the $T D P-43^{A 315 T}$ mouse models of ALS [33,73], and are 
reminiscent of the cortical hyperexcitability that characterizes ALS patients [67]. Future celltype specific genetic ablation experiments could further inform on the contribution of individual populations of neurons and glia to cortical circuit dysfunction and impairment on the downstream targets of the cerebral cortex. Such approaches have allowed to better define the contributions of MN [4], microglia [4,68], astrocytes [69] and muscles [45] to ALS onset and progression. Together, these studies and ours indicate that cerebral cortex and SubCerPN may rather be involved in disease onset, while $\mathrm{MN}$ and glia may rather modulate disease progression.

\section{Lack of SubCerPN attenuates weight loss}

Far above the cortico-motoneuronal axis, ALS affects the whole-body physiology and in particular energy metabolism. Weight loss of ALS patients is now acknowledged to start long before motor symptoms appearance, and massive weight loss negatively correlates with survival [16,17,51]. Energy homeostasis dysfunction is likely to arise, at least partly, from impairment of the hypothalamus, a subcortical structure implicated in food intake and weight control [64]. Clear hypothalamic atrophy is present in ALS patients, as well as presymptomatic gene carriers, and hypothalamic volume has been negatively correlated to disease onset [25]. While the hypothalamus is known to receive indirect control from the prefrontal cortex via the amygdala, it may also, at least in the rat, be under direct control of the medial prefrontal cortex via its layer V SubCerPN [55]. It is thus possible that the cerebral cortex and its corticofugal outputs also contribute, at least partly, to weight loss in ALS. Such a scenario would require further investigation of the hypothalamus and the energy metabolism of mice that lack SubCerPN. 


\section{Absence of CSN limits hyperreflexia, MN loss and NMJ dismantlement}

Absence of SubCerPN in $\operatorname{Sod} 1^{G 86 R}$ mice is beneficial to MN connection to their muscular targets, as assessed by the improvement of the motor performances, during the course of the disease, of double mutant mice compared to single mutant mice, and by increased numbers of $\mathrm{MN}$ and innervated NMJ at disease end-stage in $\mathrm{KO} / \mathrm{Sod} 1$ versus Sodl animals. Our data indicate that this mitigation of signs of $\mathrm{MN}$ degeneration was accompanied by amelioration of hyperreflexia, a feature of the upper motor neuron syndrome $[31,61]$. We evaluated hyperreflexia by detecting the H-reflex in the abductor digiti minimi muscle upon stimulation of the sciatic nerve, and quantifying the $\mathrm{H} / \mathrm{M}$ ratio, as previously reported $[3,47]$. Absence of H-reflex recording in $W T$ animals does not rule out the existence of a small amplitude H-reflex in these animals, below the detection threshold of our recording set-up, as already observed [47]. In contrast, presence of an H-reflex in a subgroup of pre-symptomatic Sod1 animals suggest that hyperreflexia may take place in this mouse model of ALS, long before appearance of the motor symptoms. Importantly, this correlates with the early presymptomatic degeneration of the CSN that we reported in this mouse line [42]. Absence of $\mathrm{H}-$ reflex from $K O$ animals suggests that developmental absence of CSN and other SubCerPN may have been compensated by other supraspinal controls or by spinal network rearrangements, or both, preventing the emergence of hyperreflexia. Finally, decreased H/M ratios in KO/Sodl compared to Sodl animals indicate a decreased hyperreflexia, and a possible mitigation of the upper motor neuron syndrome in absence of CSN and other SubCerPN. Contrastingly, spasticity, assessed by emergence of the long lasting reflex (LLR) of the tail muscle of fully paralysed end-stage mice is neither prevented nor even slightly modulated by absence of SubCerPN and CSN. However, evaluation of the LLR can only be performed in paralyzed animals, and our data do not rule out that spasticity, while present in $\mathrm{KO} / \mathrm{Sod} 1$ mice, might have arisen later. Recent studies support the role of serotonergic 
neurons in the emergence of spasticity in ALS [15,20,37,49]. Our data confirm the loss of TPH2-positive serotonergic neurons in the raphe nuclei of end-stage Sod1 ${ }^{G 86 R}$ mice, independently from the presence or absence of CSN. However, loss of serotonergic neurons is a late event in $\operatorname{Sod1} 1^{G 86 R}$ mice, and for technical reasons tail LLR could not be tested earlier (i.e. before full paralysis of the animals). It is thus difficult to estimate when LLR starts, and whether it could potentially, at earlier time points, reflect CSN degeneration. Importantly, because no loss of serotonergic neurons could be detected when we recorded H-reflex, it is unlikely that in the $\operatorname{Sod} 1^{G 86 R}$ mouse model of ALS emergence of hyperreflexia, as assessed by H-reflex occurrence, could arise from serotonergic neuron degeneration. In agreement with previous reports $[15,20]$, our data suggest that tail LLR may rather reflect serotonergic neuron loss than CSN loss. We thus propose to use H-reflex and $\mathrm{H} / \mathrm{M}$ ratios as readouts of CSN degeneration and upper motor syndrome in ALS mouse models.

\section{Perspectives}

In this study, we demonstrated that absence of SubCerPN was beneficial in a mouse model of ALS, suggesting that major corticofugal projections may be detrimental to their downstream targets in a context of ALS. Yet, because the strategy we employed prevented the development of a broad neuronal population, it is possible that compensations by other nuclei have occurred. For instance, genetic ablation of the corticospinal tract in the Celsr3/Emxl mice was shown to induce both increased numbers of rubrospinal projections and of terminal ramification of monoaminergic axons [27]. Genetic ablation of adult CSN and SubCerPN would thus be particularly informative to better understand how these neurons may contribute to disease onset and progression. While our study clearly demonstrated a detrimental role of CSN and other SubCerPN in a mouse model of ALS, it did not inform on the nature of this toxic effect, i.e. whether it could arise from altered excitability and downstream glutamatergic 
excitotoxicity, or from potential propagation of misfolded SOD1 protein, or both. Selective silencing of, or selective transgene excision from the SubCerPN, along with a deep mechanistic analysis of the transcriptomic modifications that accompany CSN dysfunction and degeneration in ALS [42], may in the future provide a better understanding of the role of the cerebral cortex and its outputs to ALS, and potentially unravel new therapeutic targets. 


\section{References}

1. Arlotta P, Molyneaux BJ, Chen J, Inoue J, Kominami R, Macklis JD (2005) Neuronal subtype-specific genes that control corticospinal motor neuron development in vivo. Neuron 45:207-221. doi:10.1016/j.neuron.2004.12.036

2. Batka RJ, Brown TJ, McMillan KP, Meadows RM, Jones KJ, Haulcomb MM (2014) The need for speed in rodent locomotion analyses. Anat Rec (Hoboken) 297:1839-1864. doi:10.1002/ar.22955

3. Bennett DJ, Gorassini M, Fouad K, Sanelli L, Han Y, Cheng J (1999) Spasticity in rats with sacral spinal cord injury. J Neurotrauma 16:69-84. doi:10.1089/neu.1999.16.69

4. Boillee S, Yamanaka K, Lobsiger CS, Copeland NG, Jenkins NA, Kassiotis G, Kollias G, Cleveland DW (2006) Onset and progression in inherited ALS determined by motor neurons and microglia. Science 312:1389-1392. doi:10.1126/science.1123511

5. Braak H, Brettschneider J, Ludolph AC, Lee VM, Trojanowski JQ, Del Tredici K (2013) Amyotrophic lateral sclerosis--a model of corticofugal axonal spread. Nat Rev Neurol 9:708-714. doi:10.1038/nrneurol.2013.221

6. Brettschneider J, Del Tredici K, Toledo JB, Robinson JL, Irwin DJ, Grossman M, Suh E, Van Deerlin VM, Wood EM, Baek Y, Kwong L, Lee EB, Elman L, McCluskey L, Fang L, Feldengut S, Ludolph AC, Lee VM, Braak H, Trojanowski JQ (2013) Stages of pTDP-43 pathology in amyotrophic lateral sclerosis. Ann Neurol 74:20-38. doi:10.1002/ana.23937

7. Briggs F, Usrey WM (2009) Modulation of gamma-band activity across local cortical circuits. Front Integr Neurosci 3:15. doi:10.3389/neuro.07.015.2009

8. Brown RH, Al-Chalabi A (2017) Amyotrophic Lateral Sclerosis. N Engl J Med 377:162172. doi:10.1056/NEJMra1603471

9. Caballero-Garrido E, Pena-Philippides JC, Galochkina Z, Erhardt E, Roitbak T (2017) Characterization of long-term gait deficits in mouse dMCAO, using the CatWalk system. Behav Brain Res 331:282-296. doi:10.1016/j.bbr.2017.05.042

10. Carlson CG, Rutter J, Bledsoe C, Singh R, Hoff H, Bruemmer K, Sesti J, Gatti F, Berge J, McCarthy L (2010) A simple protocol for assessing inter-trial and inter-examiner reliability for two noninvasive measures of limb muscle strength. J Neurosci Methods 186:226-230. doi:10.1016/j.jneumeth.2009.11.006

11. Charcot J-M (1869) Deux cas d'atrophie musculaire progressive avec lesions de la substance grice et des faisceaux anterolateraux de la moelle epiniere. Arch Physiol Norm Pathol 2:354,629,744

12. Chen B, Schaevitz LR, McConnell SK (2005) Fezl regulates the differentiation and axon targeting of layer 5 subcortical projection neurons in cerebral cortex. Proc Natl Acad Sci U S A 102:17184-17189. doi:10.1073/pnas.0508732102

13. Chen B, Wang SS, Hattox AM, Rayburn H, Nelson SB, McConnell SK (2008) The Fezf2Ctip2 genetic pathway regulates the fate choice of subcortical projection neurons in the developing cerebral cortex. Proc Natl Acad Sci U S A 105:11382-11387. doi:10.1073/pnas.0804918105

14. Chiò A, Pagani M, Agosta F, Calvo A, Cistaro A, Filippi M (2014) Neuroimaging in amyotrophic lateral sclerosis: insights into structural and functional changes. The Lancet Neurology 13:1228-1240. doi:10.1016/s1474-4422(14)70167-x 
15. Dentel C, Palamiuc L, Henriques A, Lannes B, Spreux-Varoquaux O, Gutknecht L, Rene F, Echaniz-Laguna A, Gonzalez de Aguilar JL, Lesch KP, Meininger V, Loeffler JP, Dupuis L (2013) Degeneration of serotonergic neurons in amyotrophic lateral sclerosis: a link to spasticity. Brain 136:483-493. doi:10.1093/brain/aws274

16. Dupuis L, Oudart H, Rene F, Gonzalez de Aguilar JL, Loeffler JP (2004) Evidence for defective energy homeostasis in amyotrophic lateral sclerosis: benefit of a high-energy diet in a transgenic mouse model. Proc Natl Acad Sci U S A 101:11159-11164. doi:10.1073/pnas.0402026101

17. Dupuis L, Pradat PF, Ludolph AC, Loeffler JP (2011) Energy metabolism in amyotrophic lateral sclerosis. Lancet Neurol 10:75-82. doi:10.1016/s1474-4422(10)70224-6

18. Eisen A, Braak H, Del Tredici K, Lemon R, Ludolph AC, Kiernan MC (2017) Cortical influences drive amyotrophic lateral sclerosis. J Neurol Neurosurg Psychiatry 88:917924. doi:10.1136/jnnp-2017-315573

19. Eisen A, Kim S, Pant B (1992) Amyotrophic lateral sclerosis (ALS): a phylogenetic disease of the corticomotoneuron? Muscle Nerve 15:219-224. doi:10.1002/mus. 880150215

20. El Oussini H, Scekic-Zahirovic J, Vercruysse P, Marques C, Dirrig-Grosch S, Dieterle S, Picchiarelli G, Sinniger J, Rouaux C, Dupuis L (2017) Degeneration of serotonin neurons triggers spasticity in amyotrophic lateral sclerosis. Ann Neurol 82:444-456. doi:10.1002/ana.25030

21. Fierro B, Raimondo D, Modica A (1991) F-wave study at different stimulation rates. Electromyogr Clin Neurophysiol 31:357-360

22. Fil D, DeLoach A, Yadav S, Alkam D, MacNicol M, Singh A, Compadre CM, Goellner JJ, O'Brien CA, Fahmi T, Basnakian AG, Calingasan NY, Klessner JL, Beal FM, Peters OM, Metterville J, Brown RH, Jr., Ling KKY, Rigo F, Ozdinler PH, Kiaei M (2017) Mutant Profilin1 transgenic mice recapitulate cardinal features of motor neuron disease. Hum Mol Genet 26:686-701. doi:10.1093/hmg/ddw429

23. Fischer LR, Culver DG, Tennant P, Davis AA, Wang M, Castellano-Sanchez A, Khan J, Polak MA, Glass JD (2004) Amyotrophic lateral sclerosis is a distal axonopathy: evidence in mice and man. Experimental Neurology 185:232-240. doi:10.1016/j.expneurol.2003.10.004

24. Geevasinga N, Menon P, Ozdinler PH, Kiernan MC, Vucic S (2016) Pathophysiological and diagnostic implications of cortical dysfunction in ALS. Nat Rev Neurol 12:651-661. doi:10.1038/nrneurol.2016.140

25. Gorges M, Vercruysse P, Muller HP, Huppertz HJ, Rosenbohm A, Nagel G, Weydt P, Petersen A, Ludolph AC, Kassubek J, Dupuis L (2017) Hypothalamic atrophy is related to body mass index and age at onset in amyotrophic lateral sclerosis. J Neurol Neurosurg Psychiatry 88:1033-1041. doi:10.1136/jnnp-2017-315795

26. Gozariu M, Roth V, Keime F, Le Bars D, Willer J-C (1998) An electrophysiological investigation into the monosynaptic H-reflex in the rat. Brain Research 782:343-347. doi:10.1016/s0006-8993(97)01402-9

27. Han Q, Cao C, Ding Y, So KF, Wu W, Qu Y, Zhou L (2015) Plasticity of motor network and function in the absence of corticospinal projection. Exp Neurol 267:194-208. doi:10.1016/j.expneurol.2015.03.008 
28. Handley EE, Pitman KA, Dawkins E, Young KM, Clark RM, Jiang TC, Turner BJ, Dickson TC, Blizzard CA (2017) Synapse Dysfunction of Layer V Pyramidal Neurons Precedes Neurodegeneration in a Mouse Model of TDP-43 Proteinopathies. Cereb Cortex 27:3630-3647. doi:10.1093/cercor/bhw185

29. Hirata T, Suda Y, Nakao K, Narimatsu M, Hirano T, Hibi M (2004) Zinc finger gene fezlike functions in the formation of subplate neurons and thalamocortical axons. Dev Dyn 230:546-556. doi:10.1002/dvdy.20068

30. Hodge RD, Bakken TE, Miller JA, Smith KA, Barkan ER, Graybuck LT, Close JL, Long B, Penn O, Yao Z, Eggermont J, Hollt T, Levi BP, Shehata SI, Aevermann B, Beller A, Bertagnolli D, Brouner K, Casper T, Cobbs C, Dalley R, Dee N, Ding S-L, Ellenbogen RG, Fong O, Garren E, Goldy J, Gwinn RP, Hirschstein D, Keene CD, Keshk M, Ko AL, Lathia K, Mahfouz A, Maltzer Z, McGraw M, Nguyen TN, Nyhus J, Ojemann JG, Oldre A, Parry S, Reynolds S, Rimorin C, Shapovalova NV, Somasundaram S, Szafer A, Thomsen ER, Tieu M, Scheuermann RH, Yuste R, Sunkin SM, Lelieveldt B, Feng D, Ng L, Bernard A, Hawrylycz M, Phillips JW, Tasic B, Zeng H, Jones AR, Koch C, Lein ES (2018) Conserved cell types with divergent features between human and mouse cortex. bioRxiv:384826. doi:10.1101/384826

31. Ivanhoe CB, Reistetter TA (2004) Spasticity. American Journal of Physical Medicine \& Rehabilitation 83:S3-S9. doi:10.1097/01.Phm.0000141125.28611.3e

32. Kassubek J, Muller HP, Del Tredici K, Brettschneider J, Pinkhardt EH, Lule D, Bohm S, Braak H, Ludolph AC (2014) Diffusion tensor imaging analysis of sequential spreading of disease in amyotrophic lateral sclerosis confirms patterns of TDP-43 pathology. Brain 137:1733-1740. doi:10.1093/brain/awu090

33. Kim J, Hughes EG, Shetty AS, Arlotta P, Goff LA, Bergles DE, Brown SP (2017) Changes in the Excitability of Neocortical Neurons in a Mouse Model of Amyotrophic Lateral Sclerosis Are Not Specific to Corticospinal Neurons and Are Modulated by Advancing Disease. J Neurosci 37:9037-9053. doi:10.1523/JNEUROSCI.0811-17.2017

34. Lance JW (1980) The control of muscle tone, reflexes, and movement: Robert Wartenberg Lecture. Neurology 30:1303-1313. doi:10.1212/wnl.30.12.1303

35. Lee S, Toda T, Kiyama H, Yamashita T (2014) Weakened rate-dependent depression of Hoffmann's reflex and increased motoneuron hyperactivity after motor cortical infarction in mice. Cell Death Dis 5:e1007. doi:10.1038/cddis.2013.544

36. Lemon RN (2008) Descending pathways in motor control. Annu Rev Neurosci 31:195218. doi:10.1146/annurev.neuro.31.060407.125547

37. Li X, Murray K, Harvey PJ, Ballou EW, Bennett DJ (2007) Serotonin facilitates a persistent calcium current in motoneurons of rats with and without chronic spinal cord injury. J Neurophysiol 97:1236-1246. doi:10.1152/jn.00995.2006

38. Liu Y, Pattamatta A, Zu T, Reid T, Bardhi O, Borchelt DR, Yachnis AT, Ranum LP (2016) C9orf72 BAC Mouse Model with Motor Deficits and Neurodegenerative Features of ALS/FTD. Neuron 90:521-534. doi:10.1016/j.neuron.2016.04.005

39. Lodato S, Molyneaux BJ, Zuccaro E, Goff LA, Chen HH, Yuan W, Meleski A, Takahashi E, Mahony S, Rinn JL, Gifford DK, Arlotta P (2014) Gene co-regulation by Fezf2 selects neurotransmitter identity and connectivity of corticospinal neurons. Nat Neurosci 17:1046-1054. doi:10.1038/nn.3757 
40. Lodato S, Rouaux C, Quast KB, Jantrachotechatchawan C, Studer M, Hensch TK, Arlotta P (2011) Excitatory projection neuron subtypes control the distribution of local inhibitory interneurons in the cerebral cortex. Neuron 69:763-779. doi:10.1016/j.neuron.2011.01.015

41. Lodato S, Shetty AS, Arlotta P (2015) Cerebral cortex assembly: generating and reprogramming projection neuron diversity. Trends Neurosci 38:117-125. doi:10.1016/j.tins.2014.11.003

42. Marques C, Fischer M, Keime C, Burg T, Brunet A, Scekic-Zahirovic J, Rouaux C (2019) Early alterations of RNA metabolism and splicing from adult corticospinal neurons in an ALS mouse model. bioRxiv:667733. doi:10.1101/667733

43. Mesrati F, Vecchierini MF (2004) F-waves: neurophysiology and clinical value. Neurophysiol Clin 34:217-243. doi:10.1016/j.neucli.2004.09.005

44. Miller DJ, Bhaduri A, Sestan N, Kriegstein A (2019) Shared and derived features of cellular diversity in the human cerebral cortex. Current opinion in neurobiology 56:117124

45. Miller TM, Kim SH, Yamanaka K, Hester M, Umapathi P, Arnson H, Rizo L, Mendell JR, Gage FH, Cleveland DW, Kaspar BK (2006) Gene transfer demonstrates that muscle is not a primary target for non-cell-autonomous toxicity in familial amyotrophic lateral sclerosis. Proc Natl Acad Sci U S A 103:19546-19551. doi:10.1073/pnas.0609411103

46. Mochizuki Y, Mizutani T, Shimizu T, Kawata A (2011) Proportional neuronal loss between the primary motor and sensory cortex in amyotrophic lateral sclerosis. Neurosci Lett 503:73-75. doi:10.1016/j.neulet.2011.08.014

47. Modol L, Mancuso R, Ale A, Francos-Quijorna I, Navarro X (2014) Differential effects on KCC2 expression and spasticity of ALS and traumatic injuries to motoneurons. Front Cell Neurosci 8:7. doi:10.3389/fncel.2014.00007

48. Molyneaux BJ, Arlotta P, Hirata T, Hibi M, Macklis JD (2005) Fezl is required for the birth and specification of corticospinal motor neurons. Neuron 47:817-831. doi:10.1016/j.neuron.2005.08.030

49. Murray KC, Nakae A, Stephens MJ, Rank M, D'Amico J, Harvey PJ, Li X, Harris RL, Ballou EW, Anelli R, Heckman CJ, Mashimo T, Vavrek R, Sanelli L, Gorassini MA, Bennett DJ, Fouad K (2010) Recovery of motoneuron and locomotor function after spinal cord injury depends on constitutive activity in 5-HT2C receptors. Nat Med 16:694-700. doi:10.1038/nm.2160

50. Ozdinler PH, Benn S, Yamamoto TH, Guzel M, Brown RH, Jr., Macklis JD (2011) Corticospinal motor neurons and related subcerebral projection neurons undergo early and specific neurodegeneration in hSOD1G(9)(3)A transgenic ALS mice. J Neurosci 31:4166-4177. doi:10.1523/JNEUROSCI.4184-10.2011

51. Peter RS, Rosenbohm A, Dupuis L, Brehme T, Kassubek J, Rothenbacher D, Nagel G, Ludolph AC (2017) Life course body mass index and risk and prognosis of amyotrophic lateral sclerosis: results from the ALS registry Swabia. Eur J Epidemiol 32:901-908. doi:10.1007/s10654-017-0318-z

52. Purves D, Augustine GJ, Fitzpatrick D, Hall W, LaMantia A, McNamara J, White L (2014) Neuroscience, 2008. De Boeck, Sinauer, Sunderland, Mass 
53. Ravits J, Laurie P, Fan Y, Moore DH (2007) Implications of ALS focality: rostral-caudal distribution of lower motor neuron loss postmortem. Neurology 68:1576-1582. doi:10.1212/01.wnl.0000261045.57095.56

54. Ravits JM, La Spada AR (2009) ALS motor phenotype heterogeneity, focality, and spread: deconstructing motor neuron degeneration. Neurology 73:805-811. doi:10.1212/WNL.0b013e3181b6bbbd

55. Reppucci CJ, Petrovich GD (2016) Organization of connections between the amygdala, medial prefrontal cortex, and lateral hypothalamus: a single and double retrograde tracing study in rats. Brain Struct Funct 221:2937-2962. doi:10.1007/s00429-015-10810

56. Ripps ME, Huntley GW, Hof PR, Morrison JH, Gordon JW (1995) Transgenic mice expressing an altered murine superoxide dismutase gene provide an animal model of amyotrophic lateral sclerosis. Proc Natl Acad Sci U S A 92:689-693. doi:10.1073/pnas.92.3.689

57. Rouaux C, Arlotta P (2010) Fezf2 directs the differentiation of corticofugal neurons from striatal progenitors in vivo. Nat Neurosci 13:1345-1347. doi:10.1038/nn.2658

58. Rouaux C, Arlotta P (2013) Direct lineage reprogramming of post-mitotic callosal neurons into corticofugal neurons in vivo. Nat Cell Biol 15:214-221. doi:10.1038/ncb2660

59. Rouaux C, Panteleeva I, Rene F, Gonzalez de Aguilar JL, Echaniz-Laguna A, Dupuis L, Menger Y, Boutillier AL, Loeffler JP (2007) Sodium valproate exerts neuroprotective effects in vivo through CREB-binding protein-dependent mechanisms but does not improve survival in an amyotrophic lateral sclerosis mouse model. J Neurosci 27:55355545. doi:10.1523/jneurosci.1139-07.2007

60. Scekic-Zahirovic J, Oussini HE, Mersmann S, Drenner K, Wagner M, Sun Y, Allmeroth K, Dieterle S, Sinniger J, Dirrig-Grosch S, Rene F, Dormann D, Haass C, Ludolph AC, Lagier-Tourenne C, Storkebaum E, Dupuis L (2017) Motor neuron intrinsic and extrinsic mechanisms contribute to the pathogenesis of FUS-associated amyotrophic lateral sclerosis. Acta Neuropathol 133:887-906. doi:10.1007/s00401-017-1687-9

61. Simon NG, Lin CS, Lee M, Howells J, Vucic S, Burke D, Kiernan MC (2015) Segmental motoneuronal dysfunction is a feature of amyotrophic lateral sclerosis. Clin Neurophysiol 126:828-836. doi:10.1016/j.clinph.2014.07.029

62. Thomsen GM, Gowing G, Latter J, Chen M, Vit JP, Staggenborg K, Avalos P, Alkaslasi M, Ferraiuolo L, Likhite S, Kaspar BK, Svendsen CN (2014) Delayed disease onset and extended survival in the SOD1G93A rat model of amyotrophic lateral sclerosis after suppression of mutant SOD1 in the motor cortex. J Neurosci 34:15587-15600. doi:10.1523/JNEUROSCI.2037-14.2014

63. van Es MA, Hardiman O, Chio A, Al-Chalabi A, Pasterkamp RJ, Veldink JH, van den Berg LH (2017) Amyotrophic lateral sclerosis. The Lancet 390:2084-2098. doi:10.1016/s0140-6736(17)31287-4

64. Vercruysse P, Vieau D, Blum D, Petersen A, Dupuis L (2018) Hypothalamic Alterations in Neurodegenerative Diseases and Their Relation to Abnormal Energy Metabolism. Front Mol Neurosci 11:2. doi:10.3389/fnmol.2018.00002

65. Vergouts M, Marinangeli C, Ingelbrecht C, Genard G, Schakman O, Sternotte A, Calas AG, Hermans E (2015) Early ALS-type gait abnormalities in AMP-dependent protein 
kinase-deficient mice suggest a role for this metabolic sensor in early stages of the disease. Metab Brain Dis 30:1369-1377. doi:10.1007/s11011-015-9706-9

66. Verstraete E, Veldink JH, van den Berg LH, van den Heuvel MP (2014) Structural brain network imaging shows expanding disconnection of the motor system in amyotrophic lateral sclerosis. Hum Brain Mapp 35:1351-1361. doi:10.1002/hbm.22258

67. Vucic S, Kiernan MC (2017) Transcranial Magnetic Stimulation for the Assessment of Neurodegenerative Disease. Neurotherapeutics 14:91-106. doi:10.1007/s13311-0160487-6

68. Wang L, Gutmann DH, Roos RP (2011) Astrocyte loss of mutant SOD1 delays ALS disease onset and progression in G85R transgenic mice. Hum Mol Genet 20:286-293. doi: $10.1093 / \mathrm{hmg} / \mathrm{ddq} 463$

69. Yamanaka K, Chun SJ, Boillee S, Fujimori-Tonou N, Yamashita H, Gutmann DH, Takahashi R, Misawa H, Cleveland DW (2008) Astrocytes as determinants of disease progression in inherited amyotrophic lateral sclerosis. Nat Neurosci 11:251-253. doi:10.1038/nn2047

70. Yasvoina MV, Genc B, Jara JH, Sheets PL, Quinlan KA, Milosevic A, Shepherd GM, Heckman CJ, Ozdinler PH (2013) eGFP expression under UCHL1 promoter genetically labels corticospinal motor neurons and a subpopulation of degeneration-resistant spinal motor neurons in an ALS mouse model. J Neurosci 33:7890-7904. doi:10.1523/JNEUROSCI.2787-12.2013

71. Zang DW, Cheema SS (2002) Degeneration of corticospinal and bulbospinal systems in the superoxide dismutase 1G93A G1H transgenic mouse model of familial amyotrophic lateral sclerosis. Neuroscience Letters 332:99-102. doi:10.1016/s0304-3940(02)00944-8

72. Zhang Q, Mao C, Jin J, Niu C, Bai L, Dang J, Zhang M (2014) Side of limb-onset predicts laterality of gray matter loss in amyotrophic lateral sclerosis. Biomed Res Int 2014:473250. doi:10.1155/2014/473250

73. Zhang W, Zhang L, Liang B, Schroeder D, Zhang ZW, Cox GA, Li Y, Lin DT (2016) Hyperactive somatostatin interneurons contribute to excitotoxicity in neurodegenerative disorders. Nat Neurosci 19:557-559. doi:10.1038/nn.4257 


\section{Figure legends}

Fig. 1 Generation of a mouse model overexpressing the $\operatorname{Sod} 1^{G 86 R}$ transgene but lacking all SubCerPN, including the CSN. a Schematic of the crossbreeding of the Sod1 ${ }^{G 86 R}$ and Fezf2 ${ }^{-/}$ mouse lines to generate four genotypes of interest: $W T, K O$, Sodl and KO/Sodl. b Retrograde labelling of the CSN from the spinal cord of $K O$ animals (right) and $W T$ (left) showing absence of $\mathrm{CSN}$ in $K O$ mice. $\mathrm{N}=5$ for all genotypes. c Representative images of brain coronal sections, at the level of the motor cortex, showing CTIP2 immunolabelling of layer $\mathrm{V}$ SubCerPN and of layer VI CThPN in WT and Sodl mice, and confirming the absence of cortical layer $\mathrm{V}$ SubCerPN from the $K O$ and $K O / \operatorname{Sod} 1$ animals. $\mathrm{N}=3$ for all genotypes. d qPCR analysis of Fezf2, Sodl and Chat expression in the cerebral cortex and spinal cord indicating that absence of Fezf2 does not affect Sod1 or Chat expression; 2-way ANOVA; $\mathrm{N}=4 \mathrm{WT}, 4 \mathrm{KO}, 4 \operatorname{Sod} 1,2 \mathrm{KO} / \mathrm{Sod} 1 ; * * * \mathrm{p}<0.001$; Scale bar $=400 \mu \mathrm{m}$ in upper panels and $200 \mu \mathrm{m}$ in lower panels of $\mathbf{b}$, and $250 \mu \mathrm{m}$ in $\mathbf{c}$.

Fig. 2 Absence of SubCerPN delays onset, prevents weight loss, and prolongs survival of Sod $1^{G 86 R}$ mice. a Bar graph representing the average weight of the four groups of mice at the beginning of the survival study (75 days); 1-way ANOVA. b Graphical representation of the evolution of the weight over time for the four genotypes. Note that while Sodl mice clearly lost weight, $\mathrm{KO} / \mathrm{Sod} 1$ mice rather stopped gaining weight; linear mixed effects model. c-d Kaplan-Meier plots of disease onset, define as the time when animals stopped gaining weight (c), and survival (d) in days, for Sod 1 and $K O / S o d 1$ mice; log-rank test (Mantel-Cox). e-f Bar graphs representing disease duration in days (e) and the percentage of weight loss during the course of the disease (f); Student unpaired t-test. For all data, $\mathrm{N}=23 \mathrm{WT}, 22 \mathrm{KO}, 14$ Sod1, 17 KO/Sod1; ** $\mathrm{p}<0.01 ; * * * \mathrm{p}<0.001$. 
Fig. 3 Absence of SubCerPN delays onset of motor symptoms and slows the decline of motor capacities. a-c Graphical representation of motor capacities over time, in days, on the grip strength test (a), the rotarod test (b) and the inverted grid test (c); linear mixed effects model. d-f Kaplan-Meier plots of grip strength score above $150 \mathrm{~g}$ (d), maximal latency to fall from the rotarod (e) or from the inverted grid (f); log-rank test (Mantel-Cox). g-i Linear regression analysis conducted using the weight as covariate; the comparisons represented here are those of the slopes. For all data, $\mathrm{N}=23 \mathrm{WT}, 22 \mathrm{KO}, 14 \operatorname{Sod} 1,17 \mathrm{KO} / \operatorname{Sod} 1 ; * \mathrm{p}<0.05,{ }^{*} \mathrm{p}<0.01$, $* * * \mathrm{p}<0.001, \mathrm{NS}$ : non-significant.

Fig. 4 Absence of SubCerPN ameliorates gait parameters recorded on CatWalk. a-l Linear regression analyses were used to model overall evolution of the groups of animals taking into account the individual progressions of each mouse over time. Weight was used as a covariate in $\mathbf{a}-\mathbf{b}$ and weight and speed were used as covariates in $\mathbf{c - l}$. Individual mouse traces were removed (b-l) to ease visualization of the regression curves (compare $\mathbf{b}$ to $\mathbf{a}$ ). The comparisons represented here are those of the slopes. For all data, $\mathrm{N}=23 \mathrm{WT}, 22 \mathrm{KO}, 14$ Sod1, $17 \mathrm{KO} / \operatorname{Sod} 1{ }^{*} \mathrm{p}<0.05, * * \mathrm{p}<0.01,{ }^{* * *} \mathrm{p}<0.001, \mathrm{NS}$ : non-significant.

Fig. 5 Absence of CSN partially prevents degeneration of the MN cell bodies and NMJ dismantlement. a Representative immunohistochemistry images of the ventral horn of the lumbar spinal cord from end-stage Sodl and KO/Sodl mice and their aged-matched WT and KO littermates, showing Choline AcetylTransferase- (ChAT-) positive neurons. b Bar graph representing the average number of ventral ChAT-positive neurons per lumbar spinal cord hemi-section; 1-way ANOVA; $\mathrm{N}=6 \mathrm{WT}, 6 \mathrm{KO}, 8 \mathrm{Sod} 1,10 \mathrm{KO} / \mathrm{Sod} 1$. c Representative 
maximum intensity projection images of z-stacks of typically innervated, partly or fully denervated neuromuscular junctions (NMJ) from end-stage $\operatorname{Sod} 1$ and $\mathrm{KO} / \mathrm{Sod} 1 \mathrm{mice}$ and their aged-matched $W T$ and $K O$ littermates. d Bar graph representing the average proportions of innervated (dark grey), partly denervated (medium grey) and fully denervated (light grey) NMJ for each genotype; 2-way ANOVA followed by Tukey multiple comparisons test; $\mathrm{N}=6$ animals per genotype. ${ }^{* *} \mathrm{p}<0.05, * * \mathrm{p}<0.01, * * * \mathrm{p}<0.001$, NS: non-significant; Scale bar: $100 \mu \mathrm{m}$ in $\mathbf{a}, 20 \mu \mathrm{m}$ in $\mathbf{c}$.

Fig. 6 Absence of CSN minimises pre-symptomatic hyperreflexia but end-stage spasticity. a Representative EMG traces of the muscular response of the abductor digiti minimi muscle upon sciatic nerve stimulation. Arrows indicate H-reflex in pre-symptomatic Sodl and $\mathrm{KO} / \mathrm{Sod} 1 \mathrm{mice} ; \mathrm{N}=6 \mathrm{WT}, 6 \mathrm{KO}, 8 \mathrm{Sod} 1,10 \mathrm{KO} / \mathrm{Sod} 1 . \mathrm{b}$ Pie charts representing the percentage of animals with an H-reflex amongst Sodl (top, blue) and KO/Sodl (bottom, red) animals; Fischer exact test. c Graph bar representing the averaged ratios of the amplitude of the $\mathrm{H}$ and $\mathrm{M}$ wave upon repeated stimulations at 0.1 and $0.2 \mathrm{~Hz}$, in $\operatorname{Sod} 1$ and $\mathrm{KO} / \mathrm{Sod} 1 \mathrm{mice}$; $\mathrm{N}=3$ Sod 1 and $3 \mathrm{KO} / \mathrm{Sod} 1$; Two-way ANOVA. d Representative EMG recordings of the tail muscle upon stimulation of end-stage, fully paralyzed and awake Sod1. Spasticity-related tail long-lasting reflex (LLR, right panels) can be observe upon stimulation (red arrow) in subgroups of animals. e Pie charts representing the percentage with a LLR amongst Sod1 (top, blue) and KO/Sod1 (bottom, red) animals; Fischer exact test; N = 8 Sod1, $11 \mathrm{KO} / \mathrm{Sod} 1$. f Signal-to-noise intensity ratios of the LLR calculated from measurements made in indicates doted boxes in $\mathbf{d}$; Student unpaired t-test; $\mathrm{N}=4$ Sodl and $7 \mathrm{KO} / \operatorname{Sod} 1 ;{ }^{*} \mathrm{p}<0.05$.

Fig. 7 Absence of SubCerPN does not prevent the late loss of serotonergic neurons in the raphe nuclei. a Schematic of the coronal section selected for TPH2-positive neurons labelling 
and counting. b Representative images of TPH 2 immunoreactivity in the brainstem (dorsal and median raphe) of end stage mice. $\mathbf{c}$ Bar graph representing the average number of TPH2positive neurons, over time (75 days, 105 days and $\mathrm{ES})$, in $W T(\mathrm{~N}=6,6$ and 4 respectively), $K O(\mathrm{~N}=5,4$ and 4 respectively), $\operatorname{Sod} 1(\mathrm{~N}=6,8$ and 4 respectively) and $K O / \operatorname{Sod} 1(\mathrm{~N}=3,5$ and 11 respectively) mice; 2-way ANOVA followed by Tukey multiple comparisons test; $* \mathrm{p}<0.05$ and $* * \mathrm{p}<0.01 ;$ Scale bar $300 \mu \mathrm{m}$.

Supplementary Fig. 1 Absence of SubCerPN does not modify the hallmarks of ALS pathology in the spinal cord. a-c Representative immunostaining images of the ventral horn of the lumbar spinal cord from end-stage Sod1 and KO/Sod1 mice and their age-matched WT and KO littermates. Sod1 and KO/Sod1 mice displayed increased GFAP (a) and IBA1 (b) immunoreactivity, as well as P62-positive aggregates (c) compare to $W T$ and $K O$ mice. $\mathrm{N}=6$ animals per genotype; Scale bar $100 \mu \mathrm{m}$.

Supplementary Fig. 2 Decreased persistence of H-Reflex with increased stimulation frequency. a Representative EMG traces of the muscular response in the abductor digiti minimi muscle upon sciatic nerve stimulation resulting from 10 stimulations at $0.1,0.2$ and $0.5 \mathrm{~Hz}$. The traces in red represent signals containing a significant response (Z-score $\geq 3)$ in the measured interval (squared in black). b Representative averaged values of the persistence of the H-Reflex at different stimulation frequencies in relation to the $0.1 \mathrm{~Hz}$ stimulation.

Supplementary Table 1 Linear regression analysis of the different motor tests and CatWalk parameters. List of parameters analysed by linear regression with either i) no covariate (left columns), ii) weight only (middle columns), iii) weight and speed as covariates (right 
columns). "4 Paws" parameters represent averages of the data of each individual paw. Analyses were performed when experiments were initiated (Origin), as well as during the whole course of the experiment (Slope); $* \mathrm{p}<0.05$; ** $\mathrm{p}<0.01$; *** $\mathrm{p}<0.001$; NS $=$ nonsignificant. 


\section{Burg et al., Figure 1}

a

F0

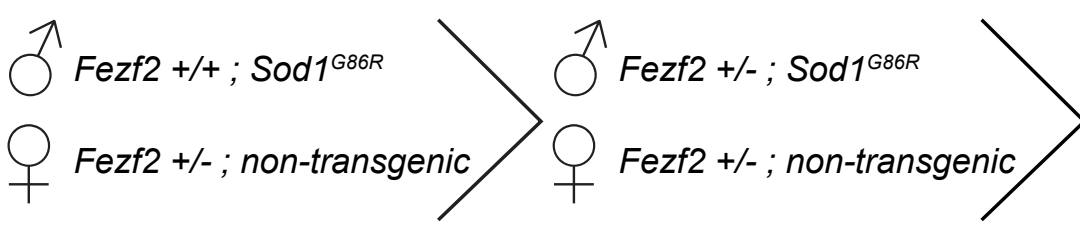

TFezf2 +/+ ; Sod $1{ }^{G 86 R}$

Fezf2 +/- ; non-transgenic

b

WT

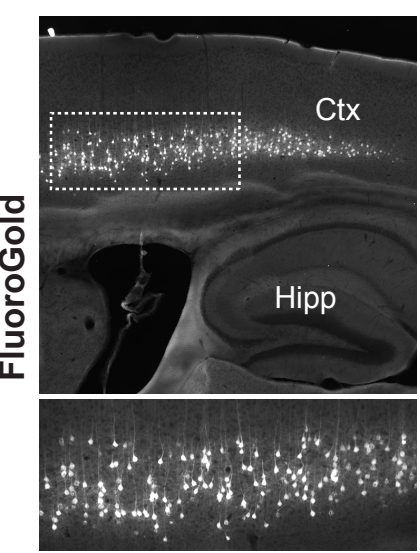

KO

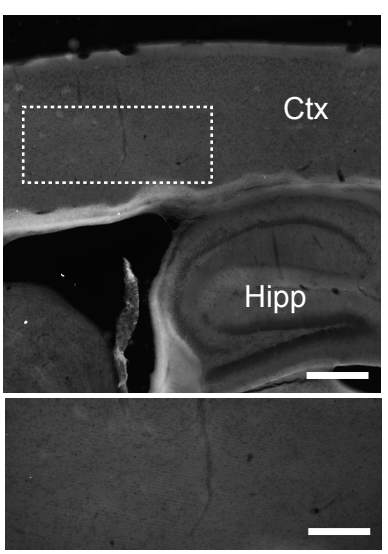

C $\quad W T$

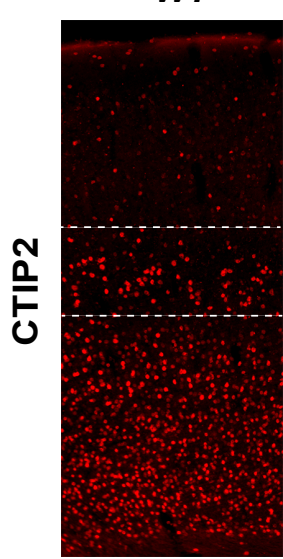

F2

Fezf2 +/+; non-transgenic $=\boldsymbol{W T}$

Fezf2 - - ; non-transgenic $=K O$

Fezf2 $+/+$; Sod1 1 G86R $=$ Sod 1

Fezf2 -/- ; Sod1 ${ }^{\mathrm{G} 86 \mathrm{R}}=\mathrm{KO} / \mathrm{Sod} 1$

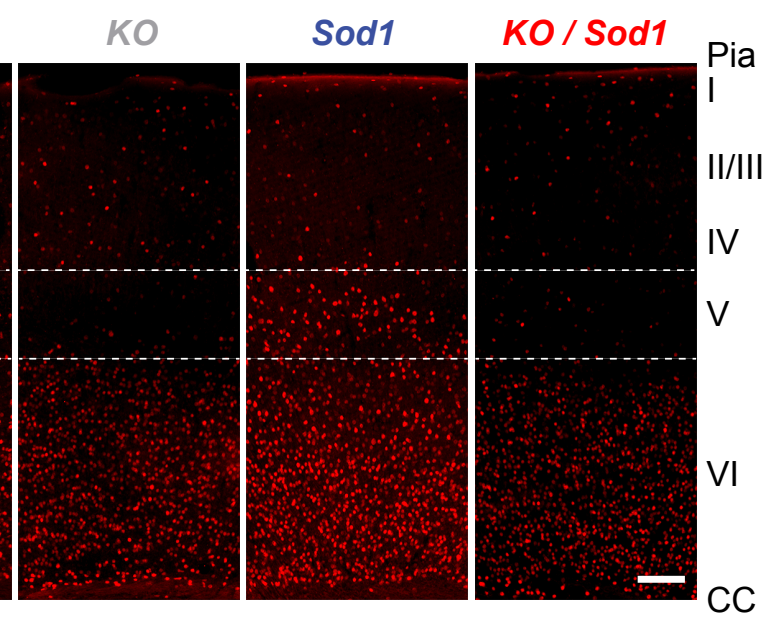

Lumbar Spinal Cord

d

Cerebral Cortex
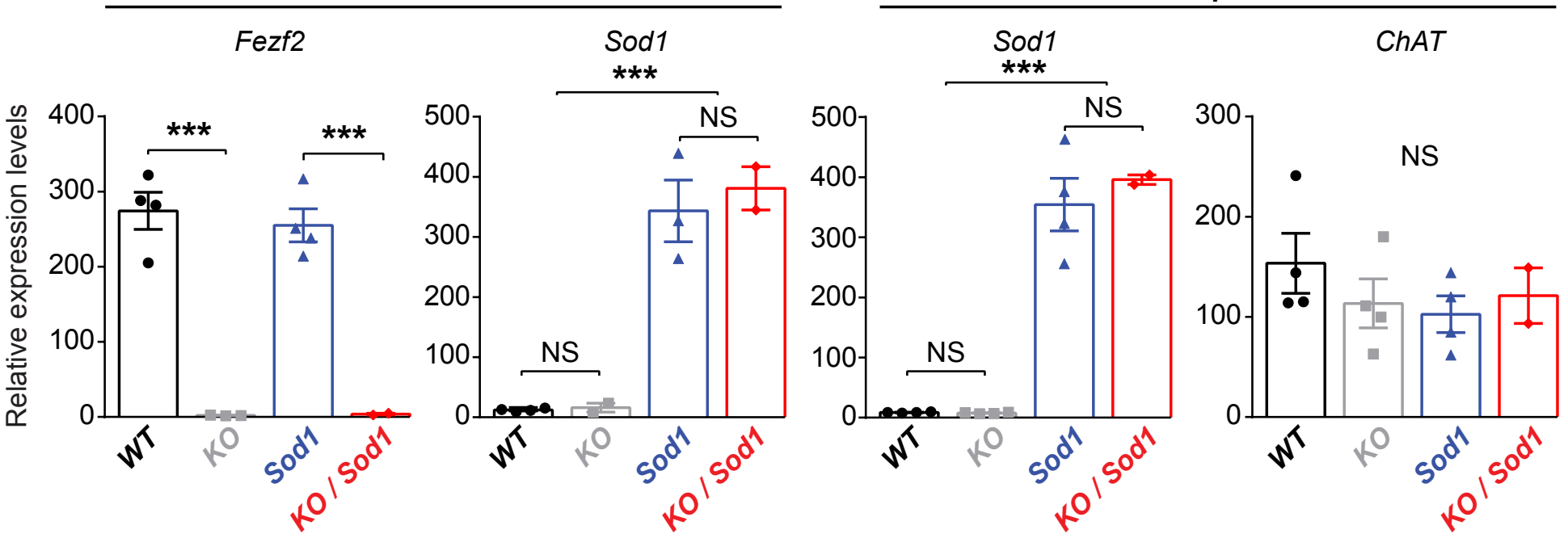


\section{Burg et al., Figure 2}

a

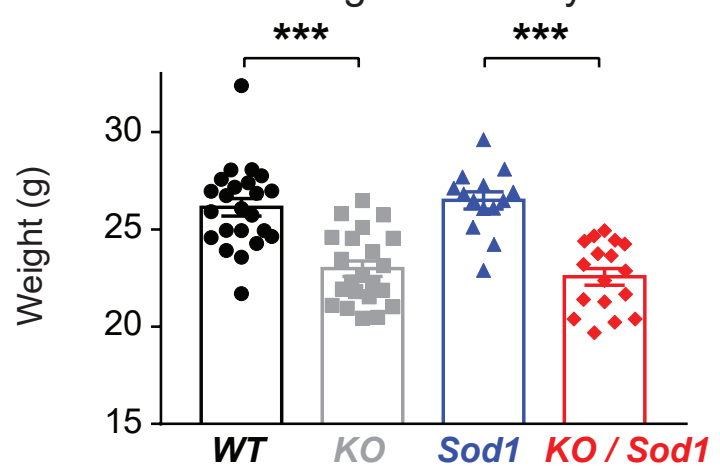

C

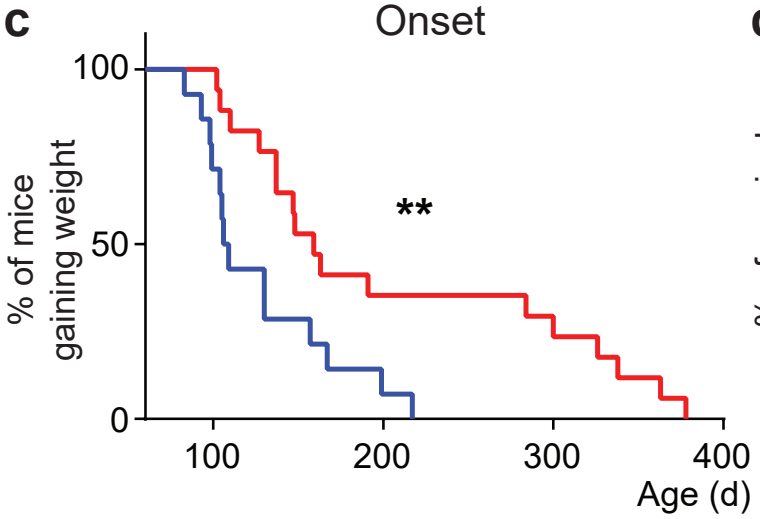

b Weight evolution
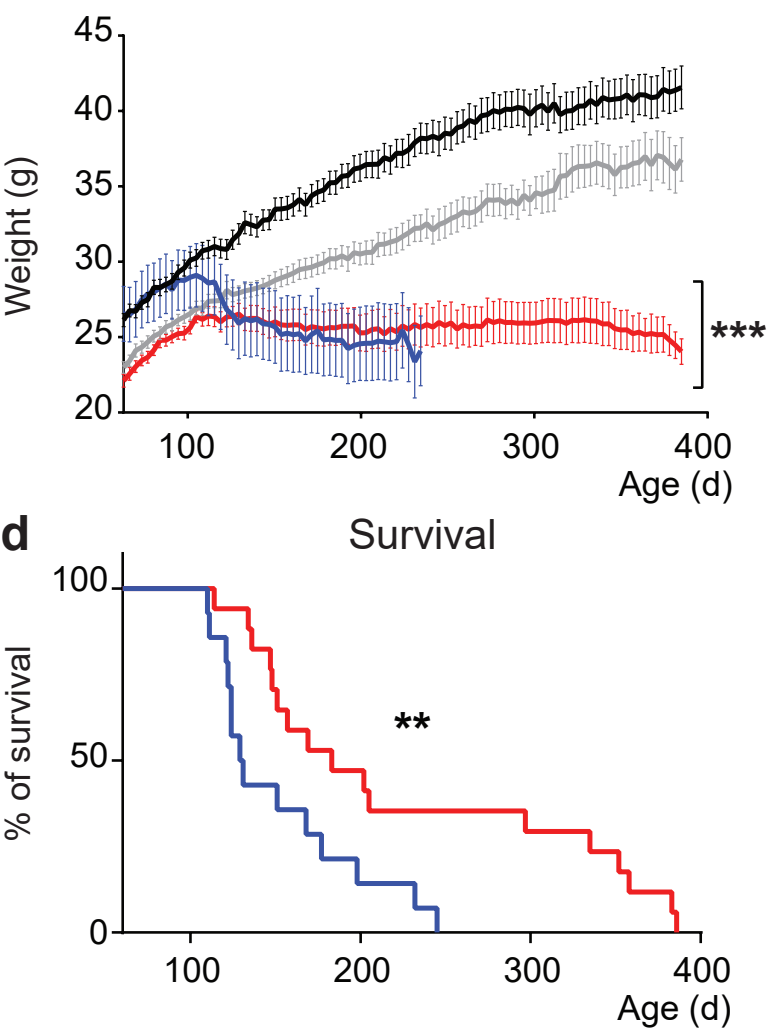

e Disease duration

f

Weight loss
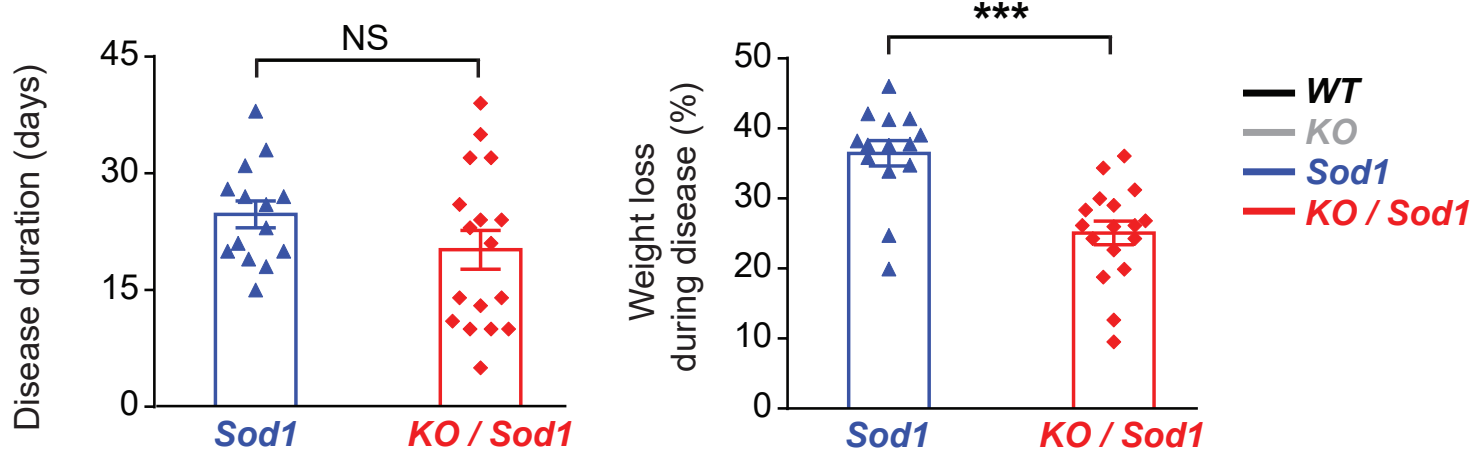


\section{Burg et al., Figure 3}

a

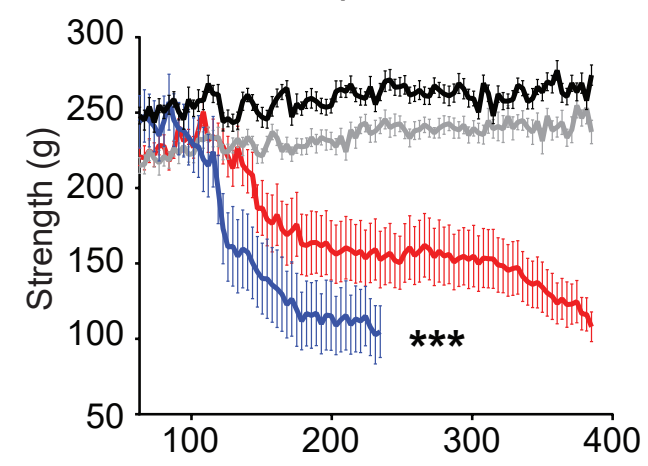

b Rotarod

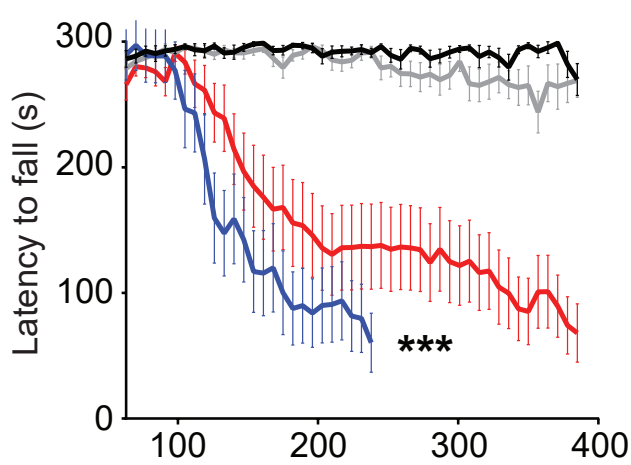

C Inverted Grid

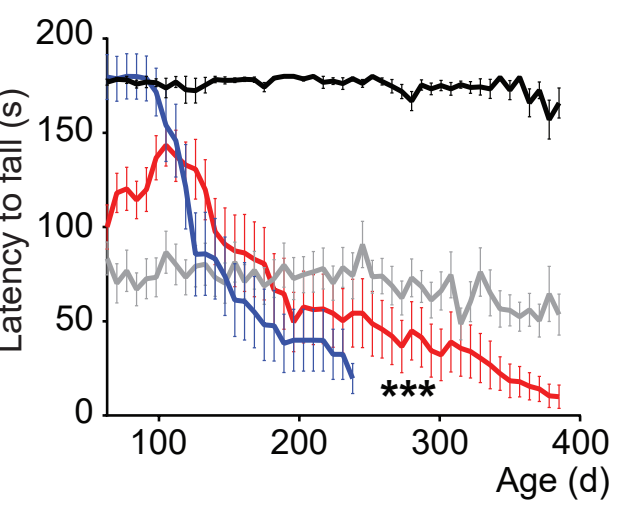

d

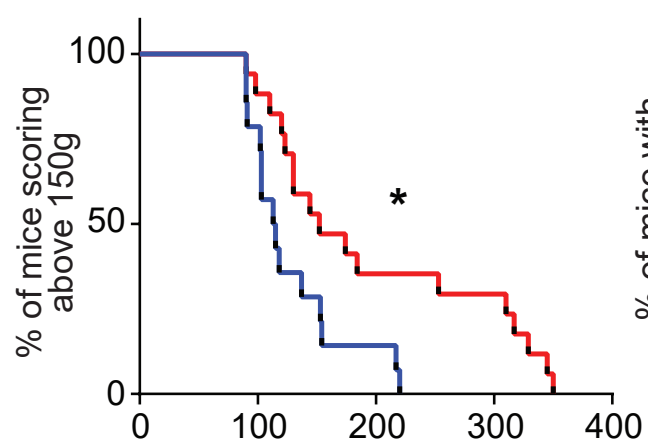

e

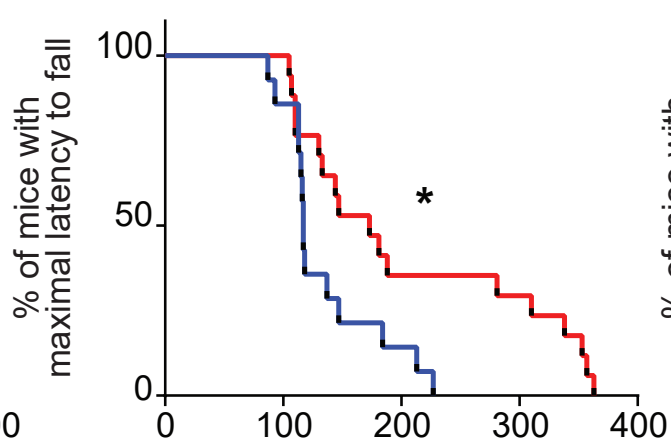

f

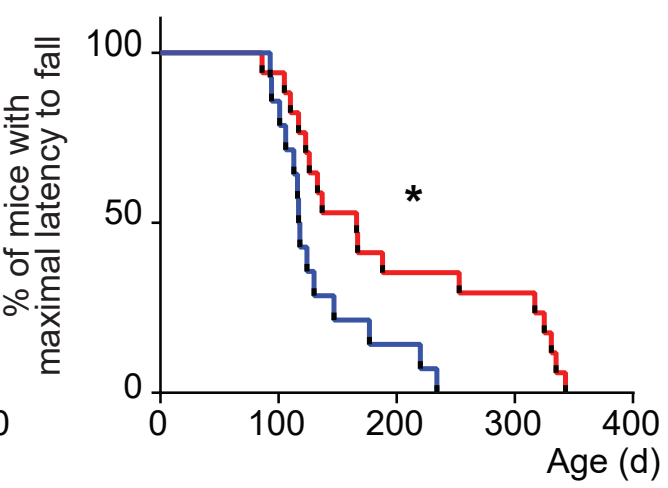

h
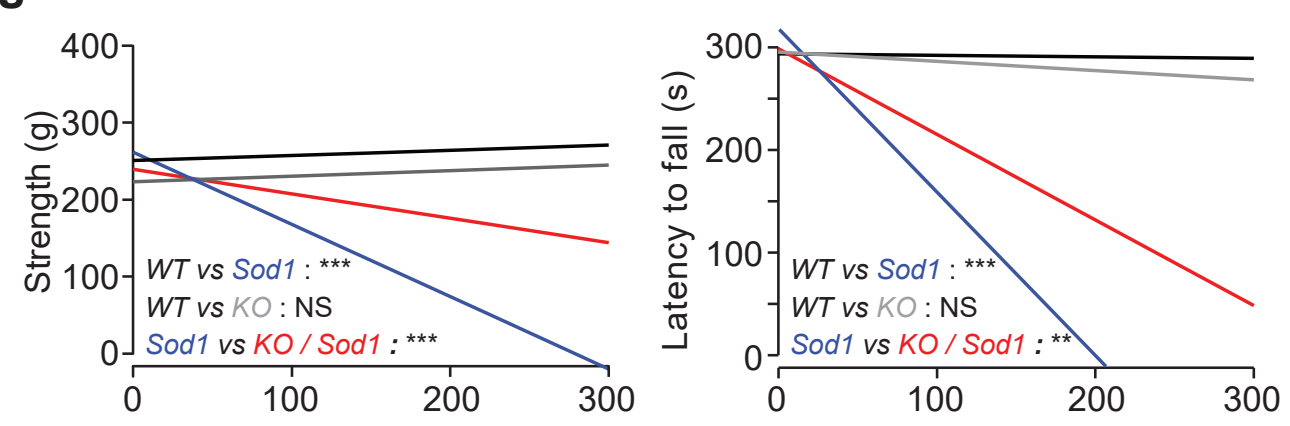

i

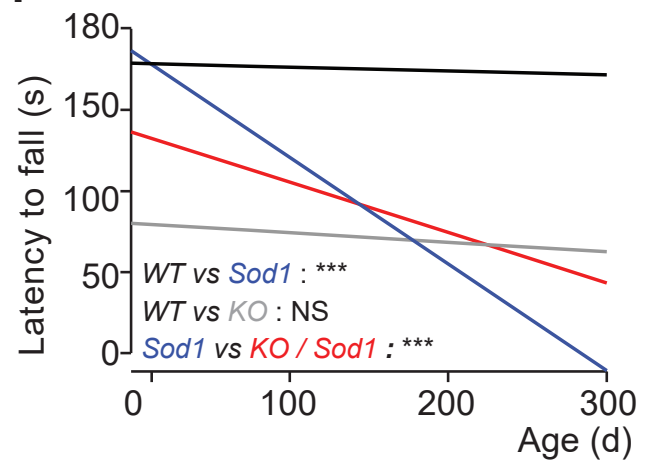


bioRxiv preprint doi: https://doi.org/10.1101/849935; this version posted November 21, 2019. The copyright holder for this preprint (which was not certified by peer review) is the author/funder. All rights reserved. No reuse allowed without permission.

\section{Burg et al., Figure 4}

a

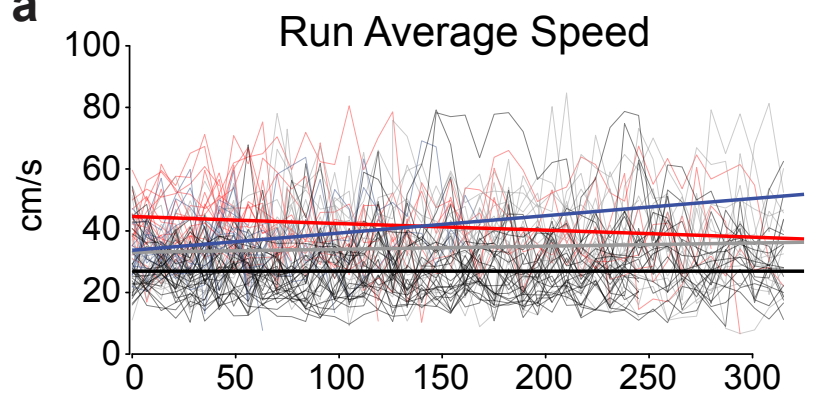

C
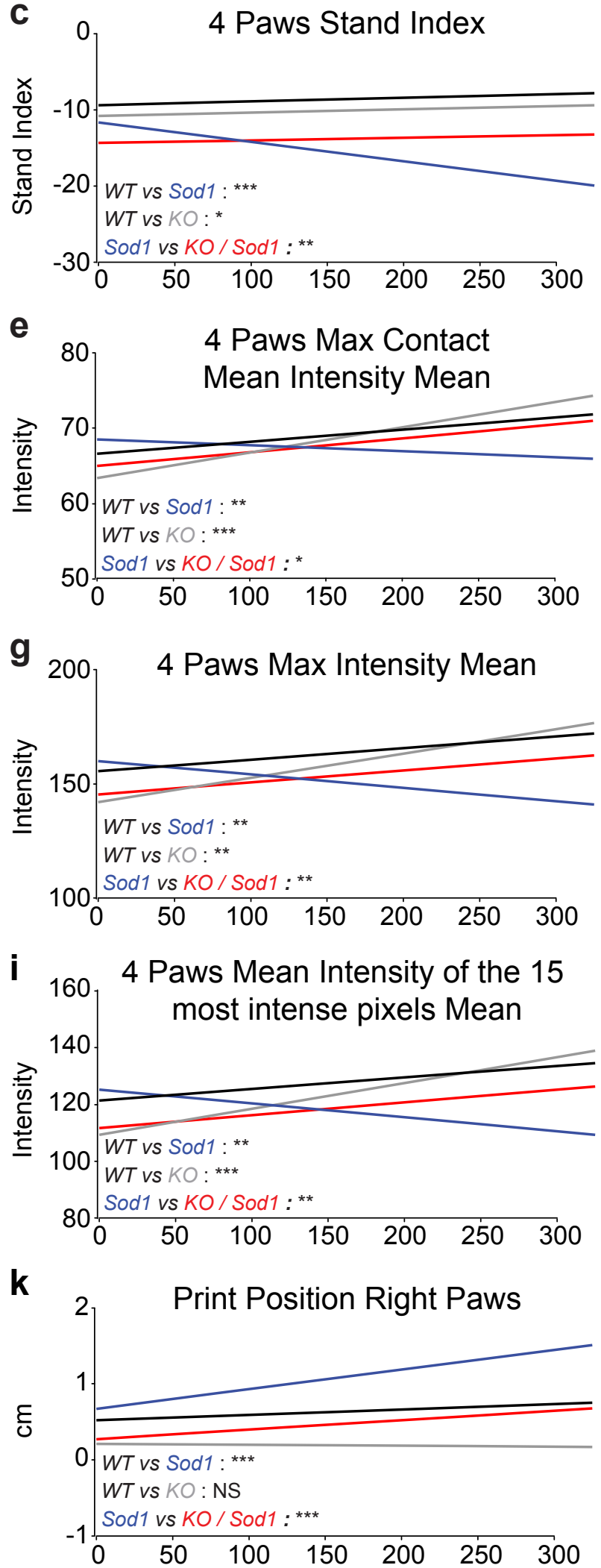
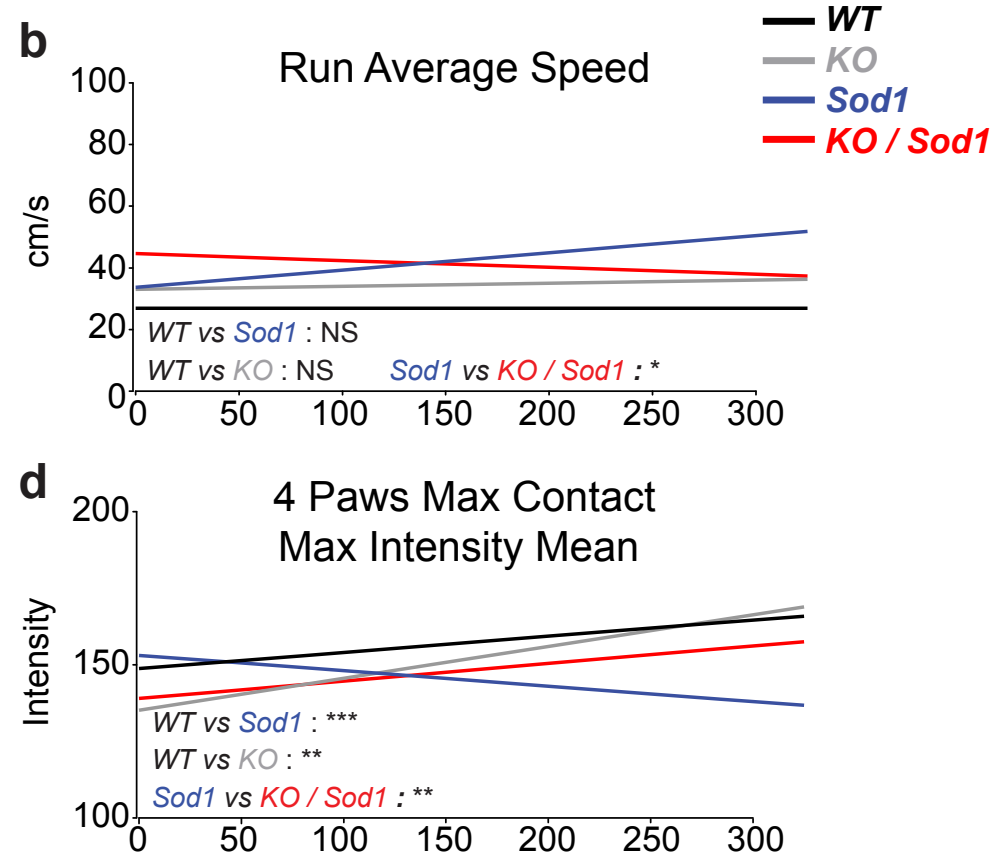

f
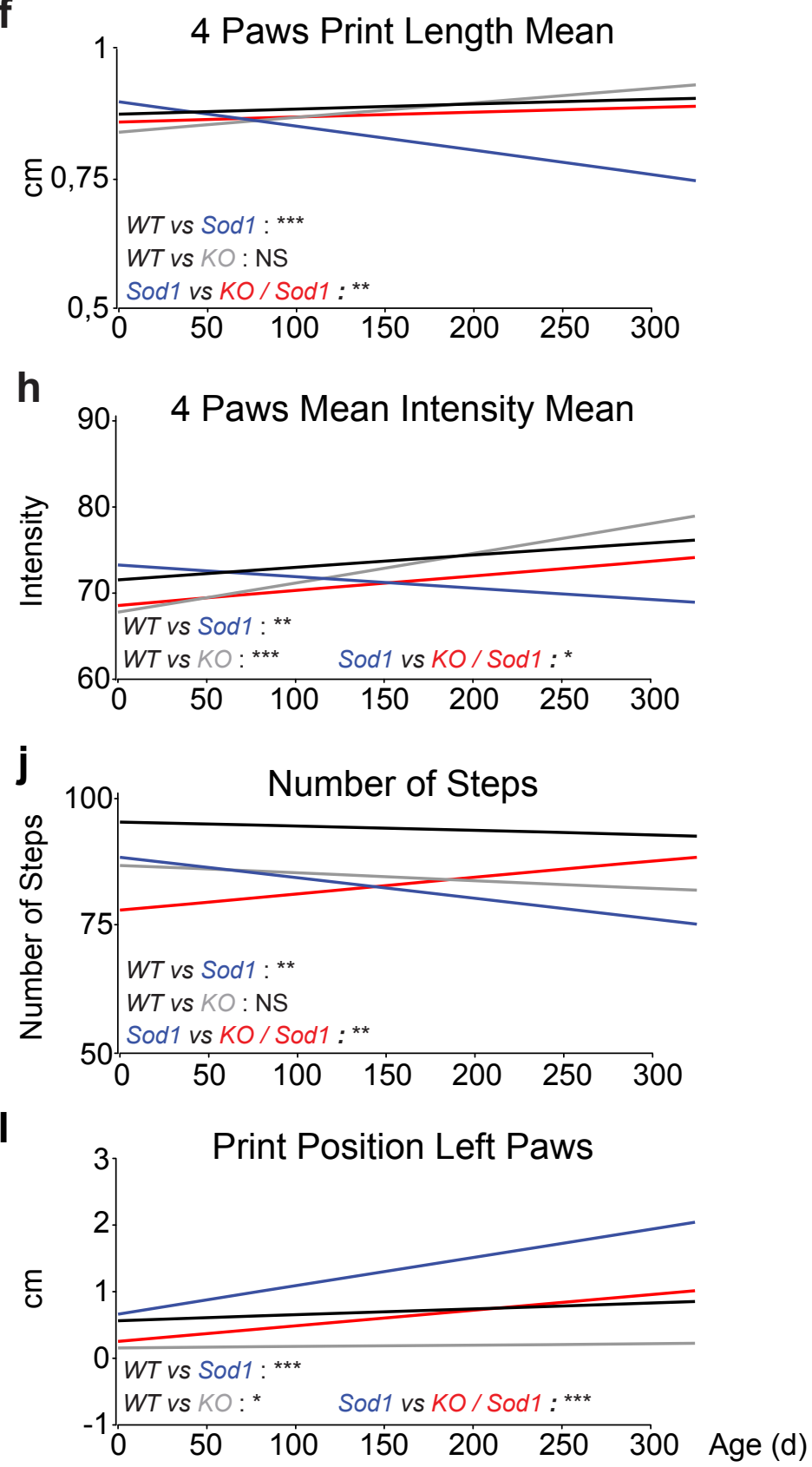


\section{Burg et al., Figure 5}
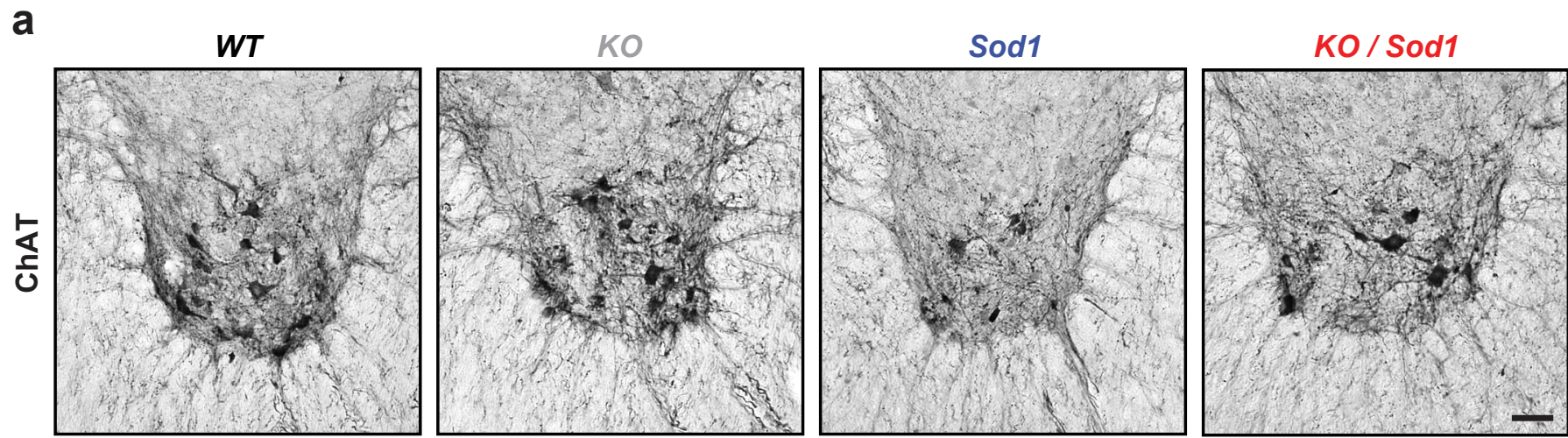

b

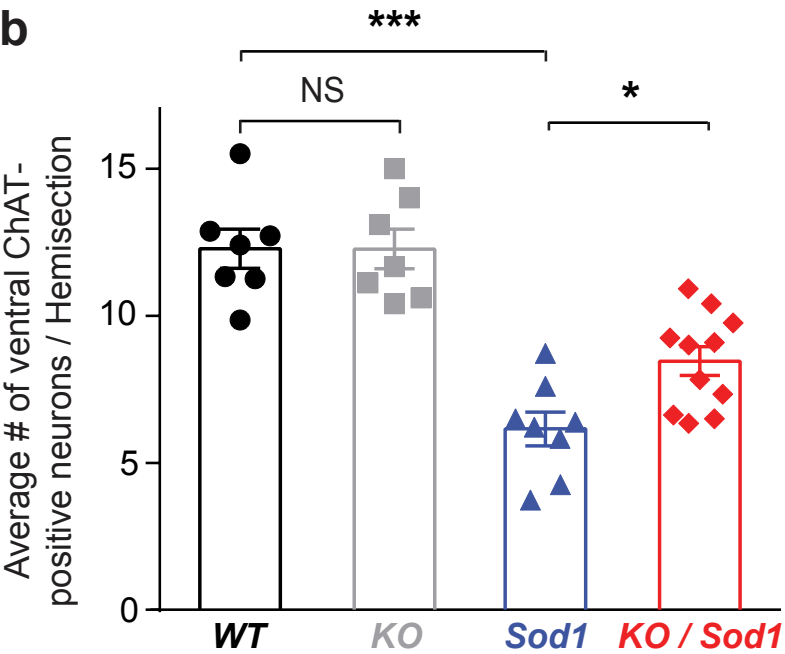

d

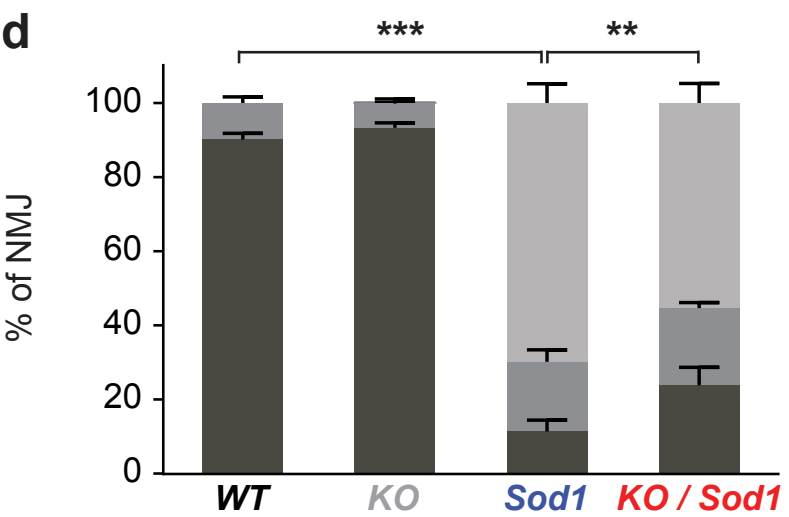

Innervated

Partially denervated

Fully denervated
C

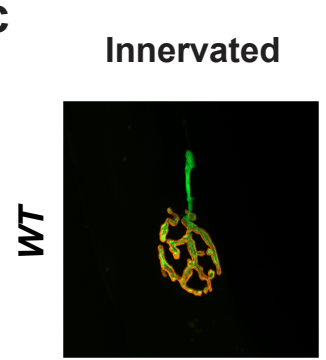

Partially denervated

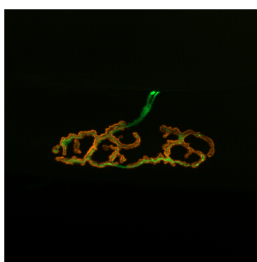

1
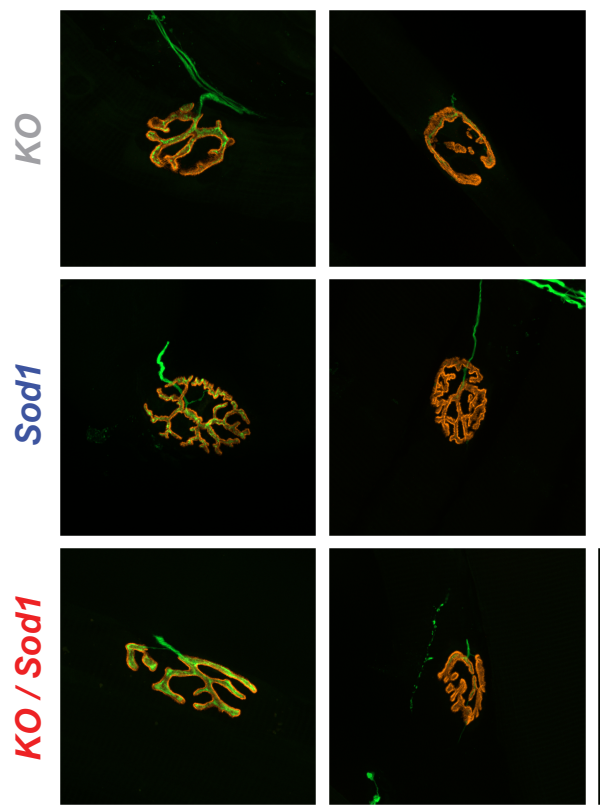
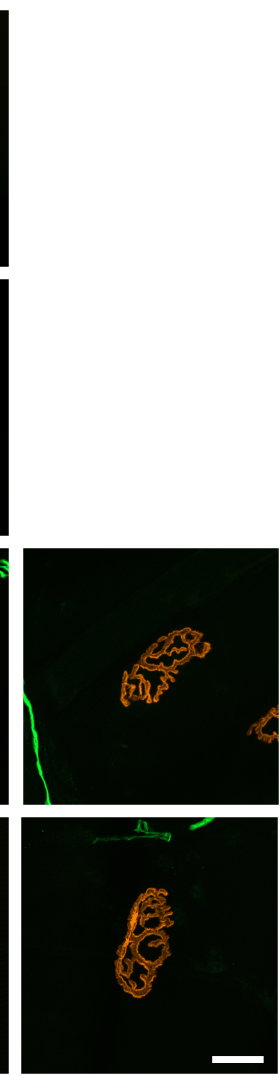

Fully denervated 
bioRxiv preprint doi: https://doi.org/10.1101/849935; this version posted November 21, 2019. The copyright holder for this preprint (which was not certified by peer review) is the author/funder. All rights reserved. No reuse allowed without permission.

\section{Burg et al., Figure 6}
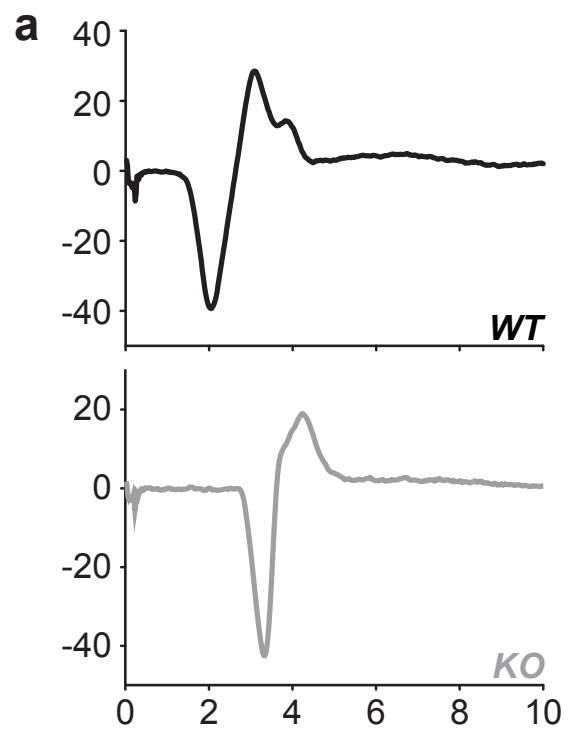

d

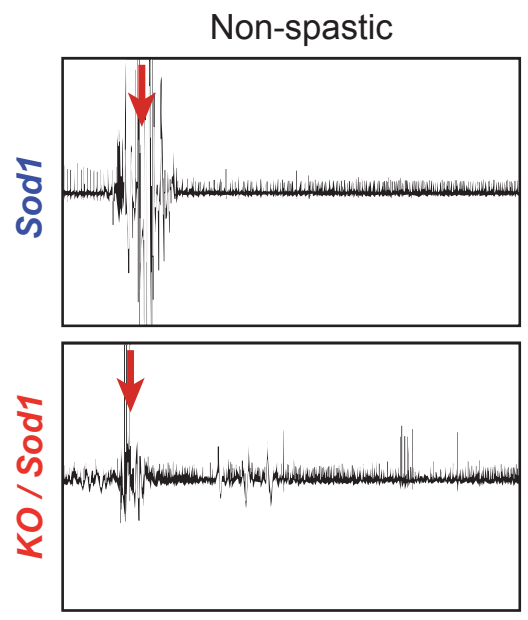

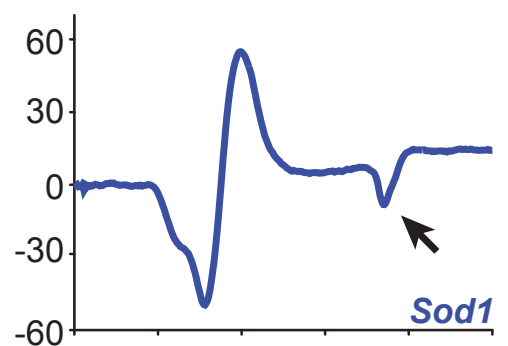
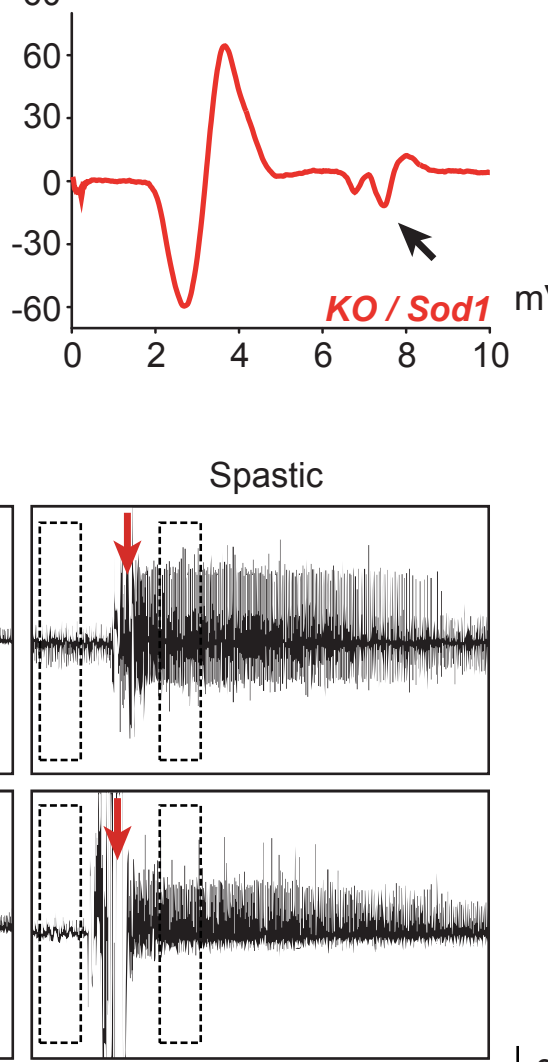

b

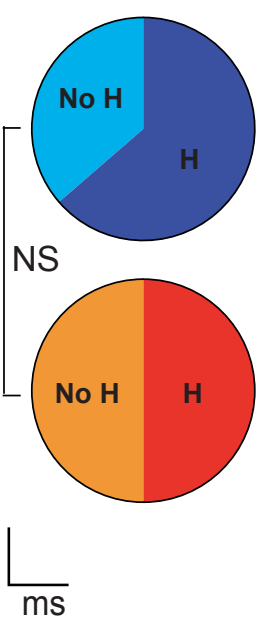

e

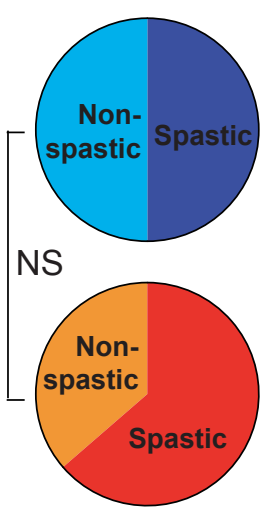

$0.2 \mathrm{mV}$
C

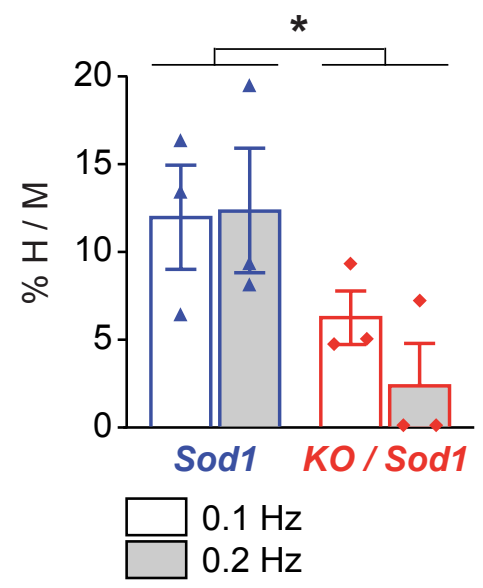

f

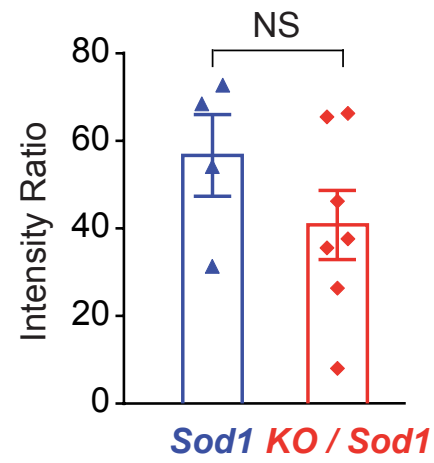


bioRxiv preprint doi: https://doi.org/10.1101/849935; this version posted November 21, 2019. The copyright holder for this preprint (which was not certified by peer review) is the author/funder. All rights reserved. No reuse allowed without permission.

\section{Burg et al., Figure 7}

a
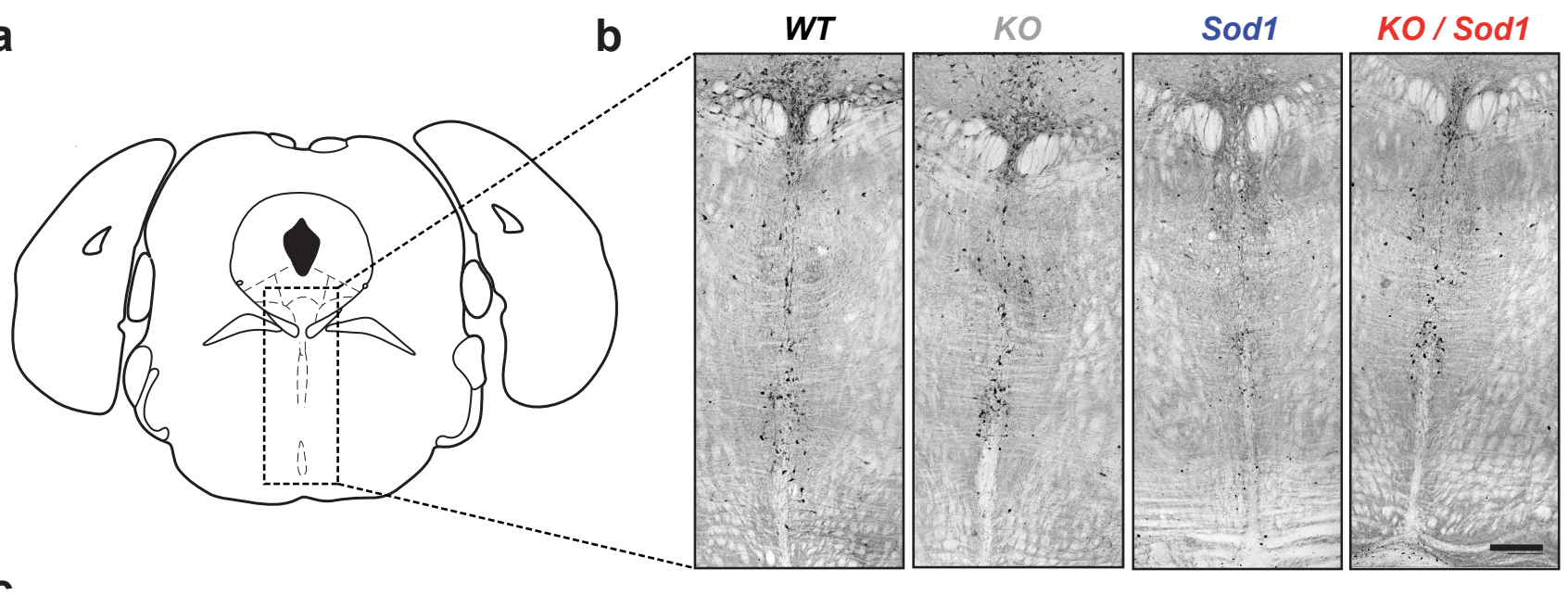

C

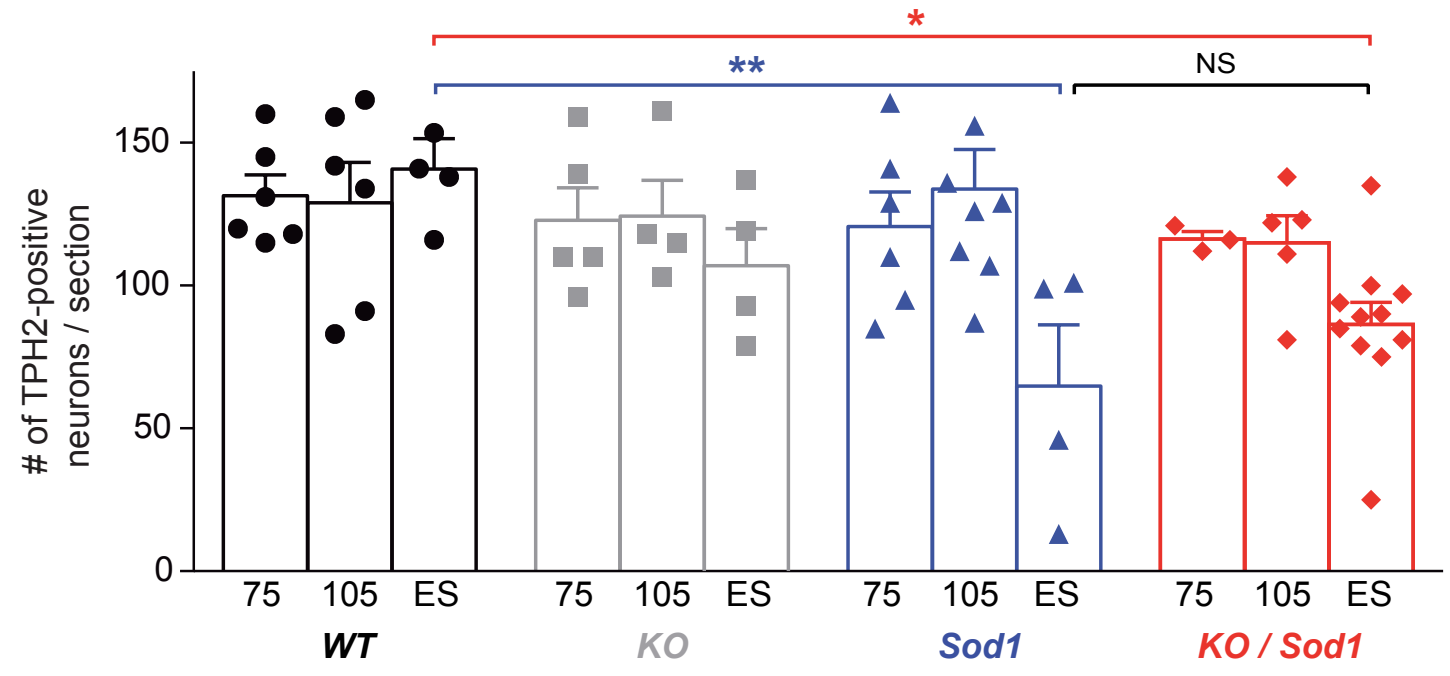


bioRxiv preprint doi: https://doi.org/10.1101/849935; this version posted November 21, 2019. The copyright holder for this preprint (which was not certified by peer review) is the author/funder. All rights reserved. No reuse allowed without permission.

\section{Burg et al., Supplementary Figure 1}

a
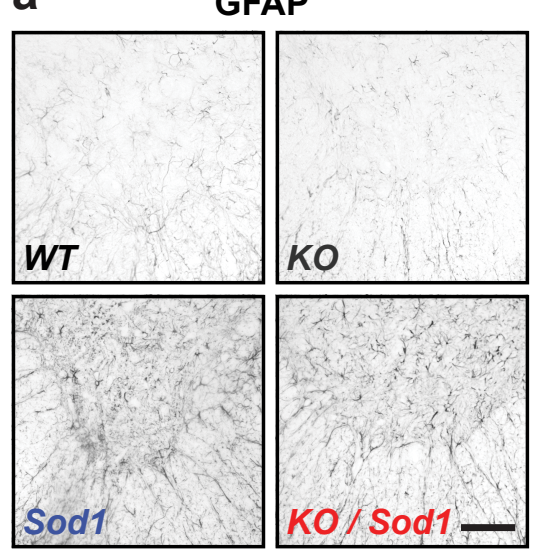

b
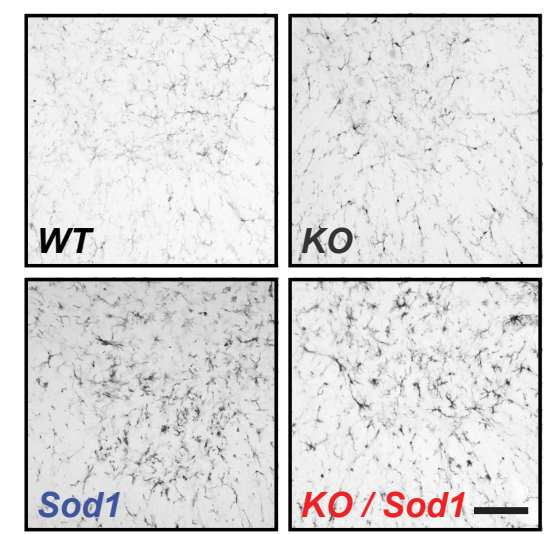

C P62
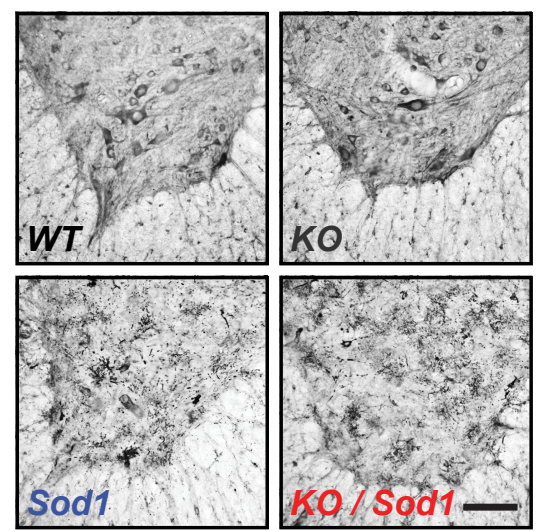
bioRxiv preprint doi: https://doi.org/10.1101/849935; this version posted November 21, 2019. The copyright holder for this preprint (which was not certified by peer review) is the author/funder. All rights reserved. No reuse allowed without permission.

\section{Burg et al., Supplementary Figure 2}
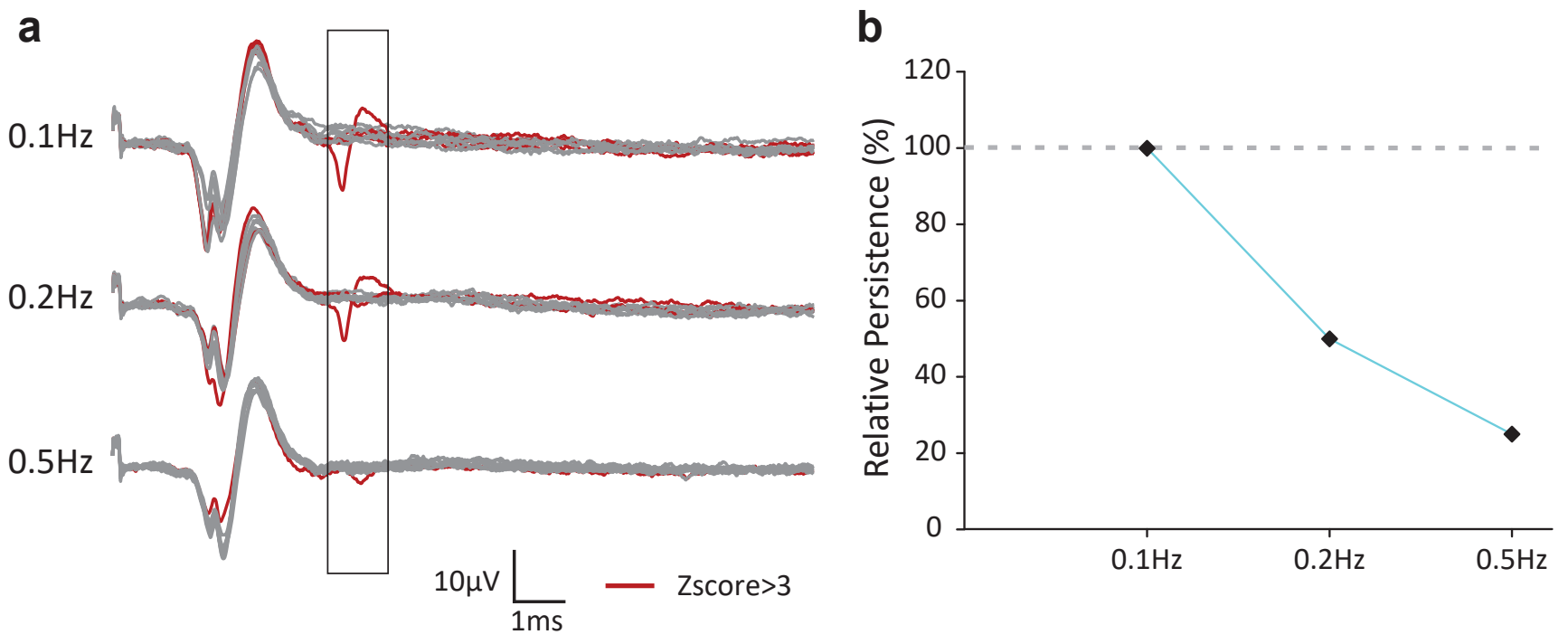